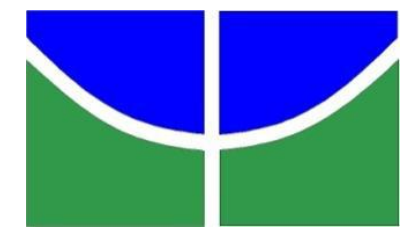

UNIVERSIDADE DE BRASÍLIA

Faculdade de Agronomia e Medicina Veterinária

Programa de Pós Graduação em Saúde Animal

\title{
CARACTERIZAÇÃO DE ASPECTOS PRODUTIVOS E SANITÁRIOS DA CRIAÇÃO DE TILÁPIA EM TANQUE REDE NO RESERVATÓRIO DE TRÊS MARIAS, MINAS GERAIS
}

GEÓRGIA DANTAS RORIZ

DISSERTAÇÃO DE MESTRADO

EM SAÚDE ANIMAL

BRASÍLIA/DF

FEVEREIRO/ 2016 


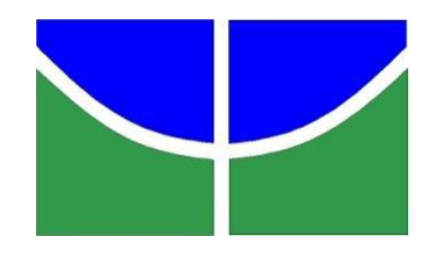

UNIVERSIDADE DE BRASÍLIA

Faculdade de Agronomia e Medicina Veterinária

Programa de Pós Graduação em Saúde Animal

\title{
CARACTERIZAÇÃO DE ASPECTOS PRODUTIVOS E SANITÁRIOS DA CRIAÇÃO DE TILÁPIA EM TANQUE REDE NO RESERVATÓRIO DE TRÊS MARIAS, MINAS GERAIS
}

GEÓRGIA DANTAS RORIZ

ORIENTADOR: PROF. DR. VITOR SALVADOR PICÃO GONÇALVES

\author{
PUBLICAÇÃO Nº 122/2016
}

DISSERTAÇÃO DE MESTRADO EM SAÚDE ANIMAL

ÁREA DE CONCENTRAÇÃO: MEDICINA PREVENTIVA E PATOLOGIA VETERINÁRIA LINHA DE PESQUISA: EPIDEMIOLOGIA, PREVENÇÃO E CONTROLE DE DOENÇAS DOS ANIMAIS E GESTÃO DOS RISCOS PARA A SAÚDE PÚBLICA

BRASÍLIA/DF

FEVEREIRO/ 2016 
UNIVERSIDADE DE BRASÍLIA

\title{
CARACTERIZAÇÃO DE ASPECTOS PRODUTIVOS E SANITÁRIOS DA CRIAÇÃO DE TILÁPIA EM TANQUE REDE NO RESERVATÓRIO DE TRÊS MARIAS, MINAS GERAIS
}

\author{
GEÓRGIA DANTAS RORIZ
}

DISSERTAÇÃO DE MESTRADO SUBMETIDA AO PROGRAMA DE PÓSGRADUAÇÃO EM SAÚdE ANIMAL, COMO PARTE DOS REQUISITOS NECESSÁRIOS A OBTENÇÃO DO GRAU DE MESTRE EM SAÚDE ANIMAL.

APROVADA POR:

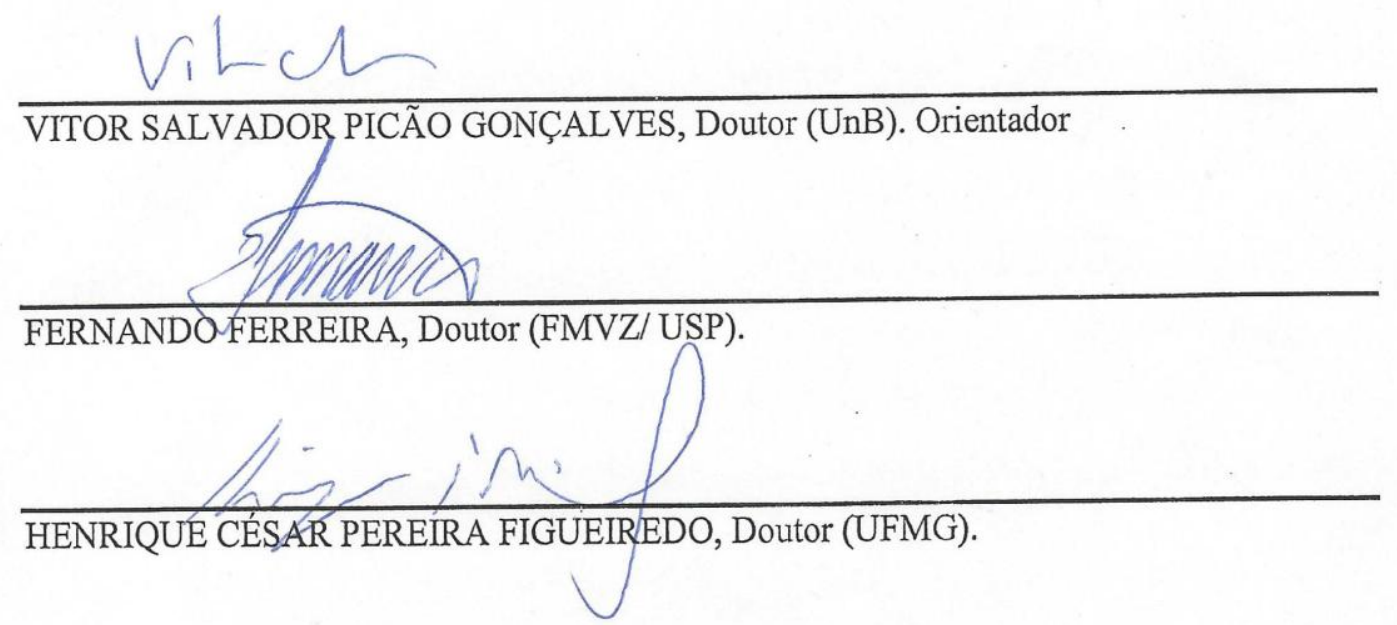

BRASÍLIA/ DF, 22 DE FEVEREIRO DE 2016 


\section{REFERÊNCIA BIBLIOGRÁFICA E CATALOGAÇÃO}

RORIZ, G. D. Caracterização de aspectos produtivos e sanitários da criação de tilápia em tanque rede no reservatório de Três Marias, Minas Gerais. Brasília: Faculdade de Agronomia e Medicina Veterinária, Universidade de Brasília, 2016, 48p. Dissertação de Mestrado.

Documento formal, autorizando reprodução desta dissertação de mestrado para empréstimo ou comercialização, exclusivamente para fins acadêmicos, foi passado pelo autor à Universidade de Brasília e acha-se arquivado na Secretaria do Programa. O autor reserva para si os outros direitos autorais, de publicação. Nenhuma parte desta dissertação de mestrado pode ser reproduzida sem a autorização por escrito do autor. Citações são estimuladas, desde que citada a fonte.

Roriz, Geórgia Dantas

Caracterização de aspectos produtivos e sanitários da criação de tilápia em tanque rede no reservatório de Três Marias, Minas Gerais / Geórgia Dantas Roriz Orientação de Vítor Salvador Picão Gonçalves.

Brasília, 2016. 48p.: il.

Dissertação de mestrado (M) - Universidade de Brasília / Faculdade de Agronomia e Medicina Veterinária, 2016.

1. Aquicultura. 2.Tanques-rede. 3.Caracterização. 4.

Reservatório. 5. Tilápia. I. RORIZ, G.D. II. Título

Agris / FAO 
“A tarefa não é tanto ver aquilo que ninguém viu, mas pensar o que ninguém ainda pensou sobre aquilo que todo mundo vê." (Arthur Schopenhauer) 


\section{AGRADECIMENTOS}

À Deus, por ser meu apoio nas horas difíceis e por me abençoar com tantas graças, amor e pessoas boas ao meu redor.

Aos meus pais: Gilberto e Elisete, que nunca mediram esforços para que eu seguisse todas as minhas escolhas e que por tantas vezes se orgulharam de mim e me fizeram acreditar que eu era capaz.

Aos meus irmãos, Guilherme e Roberta, antigos companheiros de apartamento, que sempre garantiram minhas diversões e distrações em meio a tantas coisas pelas quais passamos e que tanto me influenciaram e me auxiliaram em minhas escolhas.

Ao meu namorado Pedro, que sempre me escutou com toda a paciência, me ajudou a enxergar que não há problema que não possa ser solucionado e me cercou de carinho e amor. Também ao meu porto seguro de quatro patas: Thor.

Ao meu orientador, Prof. Vitor, por quem sempre cultivei muita admiração por toda a sua experiência e profissionalismo. Pela paciência, oportunidade, apoio e ensinamentos. Também ao Prof. Ian Gardner, por compartilhar conosco sua experiência no estudo de animais aquáticos.

Aos meus colegas de laboratório: Flávio, Geraldinho, Mariana, Janaína e Geraldo. Especialmente à Ana Lourdes, que sempre teve paciência para me ensinar, instruir e escutar e à Marina, minha grande companheira de viagens e trabalhos a campo, por compartilhar comigo toda sua experiência na área de animais aquáticos e por tantas vezes me ensinar e ajudar em meus trabalhos, além de proporcionar tantas diversões nesses trabalhos.

A toda a equipe do escritório da CODEVASF, em Morada Nova de Minas, por tornar possível a realização dos trabalhos a campo.

A todos os professores que, ao longo de todos esses anos de vida acadêmica, puderam transmitir seus conhecimentos e pelos quais tenho tanta admiração. À CAPES e ao CNPq pelo apoio financeiro. 


\section{SUMÁRIO}

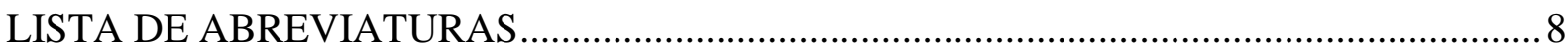

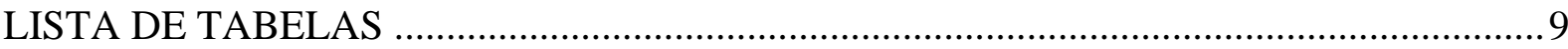

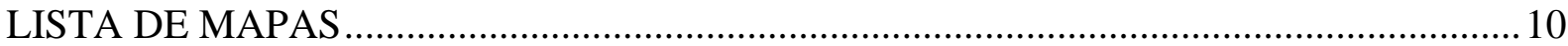

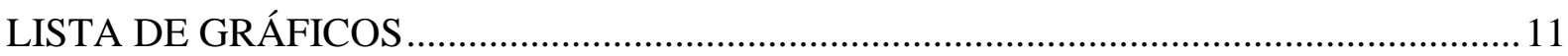

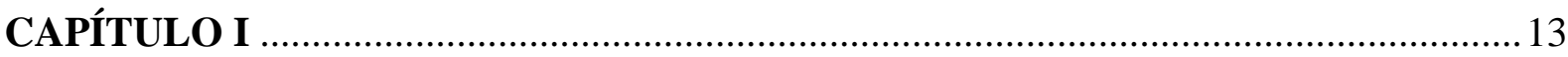

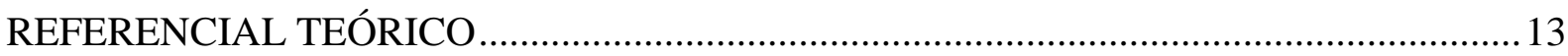

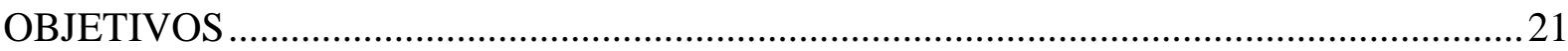

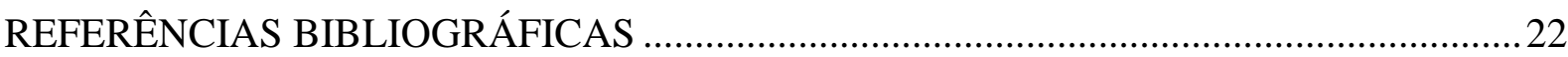

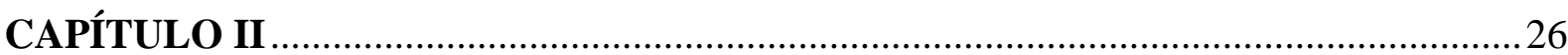

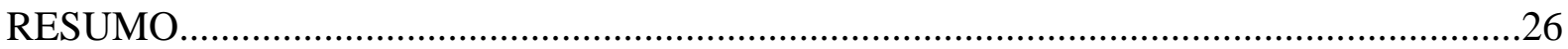

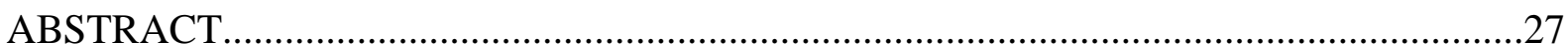

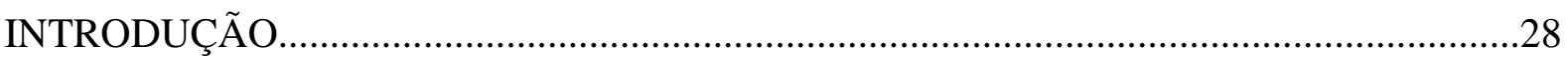

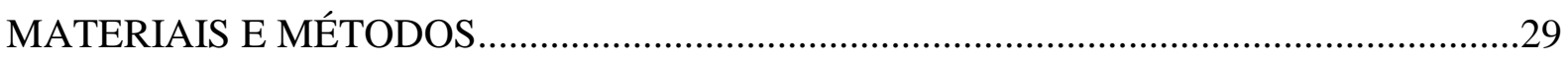

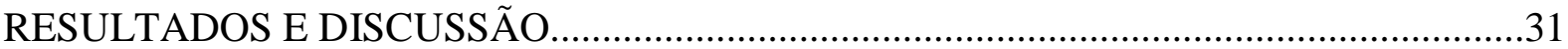

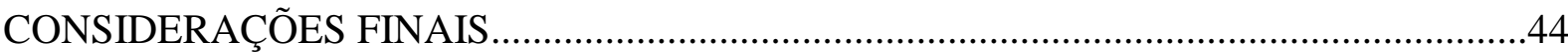

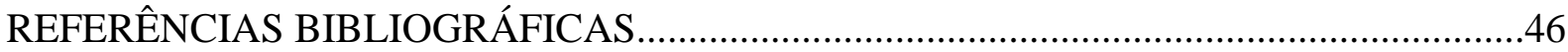




\section{LISTA DE ABREVIATURAS}

CODEVASF Companhia de Desenvolvimento dos Vales do São Francisco e Parnaíba

FAO Organização das Nações Unidas para a Alimentação e para a Agricultura

MPA Ministério da Pesca e Aquicultura

OIE Organização Mundial de Saúde Animal

SIE Serviço de Inspeção Estadual

SIF Serviço de Inspeção Federal

SIM Serviço de Inspeção Municipal 


\section{LISTA DE TABELAS}

Página

Tabela 1. Frequência do tipo de mão de obra por número de pessoas envolvidas no manejo dos animais nas pisciculturas em tanque rede do município de Morada Nova de Minas, MG.

Tabela 2. Frequência de tipo de mão de obra por realização de outras atividades remuneradas nas pisciculturas em tanque rede do município de Morada Nova de Minas, MG.

Tabela 3. Frequência de número de funcionários por realização de outras atividades remuneradas nas pisciculturas em tanque rede do município de Morada Nova de Minas, MG.

Tabela 4. Frequência de categorias de duração de ciclo de produção por peso das tilápias na despesca nas pisciculturas em tanque rede do município de Morada Nova de Minas, MG

Tabela 5. Frequência de realização de procedimentos em casos de doença ou mortalidade em tilápias nas pisciculturas em tanque rede do município de Morada Nova de Minas, MG.

Tabela 6. Frequência de relatos de problemas de qualidade da água por mudança de local de produção de produtores de peixe em tanque rede no município de Morada Nova de Minas, MG

Tabela 7. Frequência do tipo de mão de obra por tamanho de propriedade nas pisciculturas em tanque rede do município de Morada Nova de Minas, MG.

Tabela 8. Frequência de duração do ciclo de produção por tamanho de propriedade nas pisciculturas em tanque rede do município de Morada Nova de Minas, MG

Tabela 9. Frequência de avaliação da temperatura por tamanho de propriedade nas pisciculturas do município de Morada Nova de Minas, MG.

Tabela 10. Principais desafios relatados pelos produtores de tilápia em tanque-rede quanto à produção de peixes no reservatório do município de Morada

Nova de Minas, MG. 


\section{LISTA DE MAPAS}

Página

Mapa 1. Localização das pisciculturas visitadas no município de Morada Nova de Minas. 


\section{LISTA DE GRÁFICOS}

Página

Gráfico 1. Quantidade de tanques-rede por propriedade no município de Morada Nova de Minas, MG

Gráfico 2. Quantidade de alevinos introduzidos por mês por quantidade de tanques por propriedade nas pisciculturas em tanque rede no município de Morada Nova de Minas, MG.

Gráfico 3. Frequência de relatos de utilização de substâncias acrescidas à ração nas pisciculturas em tanque rede do município de Morada Nova de Minas, MG.

Gráfico 4. Duração do ciclo de produção por piscicultura em tanque rede no município de Morada Nova de Minas, MG.

Gráfico 5. Frequência de realização de procedimentos de classificação e repicagem no manejo produtivo das pisciculturas no município de Morada Nova de Minas, MG.

Gráfico 6. Frequência de produtores de peixe em tanque-rede de acordo com o destino das tilápias despescadas no município de Morada Nova de Minas, MG.

Gráfico 7. Frequência de evisceração de tilápias nas propriedades segundo destino de venda nas pisciculturas em tanque rede do município de Morada Nova de Minas, MG.

Gráfico 8. Frequência de sinais clínicos mais observados nas tilápias cultivadas no reservatório no município de Morada Nova de Minas, MG.

Gráfico 9. Frequência do destino dado aos animais mortos nas pisciculturas em tanque rede do município de Morada Nova de Minas, MG.

Gráfico 10. Destino de venda do produto final por tamanho de propriedade nas pisciculturas em tanque rede do município de Morada Nova de Minas, MG.

Gráfico 11. Destino dado aos animais mortos segundo tamanho de propriedade nas pisciculturas do município de Morada Nova de Minas, MG.

Gráfico 12. Percentual médio de perdas por ciclo da produção de tilápia em tanque-rede no município de Morada Nova de Minas, MG.

Gráfico 13. Percepção dos produtores de tilápia em tanque-rede quanto às principais causas de mortalidade de peixes em reservatórios no município de Morada Nova de Minas, MG. 


\section{INFORMAÇÕES ADICIONAIS}

O Capítulo I inclui o referencial teórico do trabalho de pesquisa, assim como os seus objetivos. O Capítulo II descreve a metodologia e resultados da pesquisa realizada e está escrito na forma de artigo completo para publicação. 


\section{CAPÍTULO I}

\section{REFERENCIAL TEÓRICO}

\section{Importância da pesca e aquicultura}

A importância de se explorar novas áreas de produção de alimentos, aliada à conservação dos recursos naturais remanescentes para as gerações futuras, apoia-se na necessidade de se pensar em meios mais eficazes de alimentar uma população global em que mais de 800 milhões de pessoas ainda sofrem de desnutrição e que se espera alcançar 9,6 bilhões de pessoas em 2050. Destaca-se nesse cenário o papel desempenhado pela pesca e aquicultura na eliminação da fome, promoção da saúde e redução da pobreza. No Brasil, as ações do governo de combate à fome incluem o uso de águas públicas da união para potencializar a produção de alimentos em áreas ainda não exploradas, garantindo o uso múltiplo das águas (FAO, 2014).

A pesca é caracterizada pela retirada de organismos aquáticos da natureza sem prévio cultivo. Diferentemente, a aquicultura caracteriza-se pelo processo de criação em cativeiro de organismos com habitat predominantemente aquático, tais como peixes, camarões, rãs, algas, entre outras espécies. As duas formas de produção de pescados podem ocorrer em escala artesanal ou industrial, tanto no mar (marinha), a qual inclui ainda operações em zonas entre marés, quanto em lagos, rios e reservatórios (continental) (SEBRAE, 2007).

Os pescados se caracterizam como um alimento extremamente nutritivo e de fácil digestão. $\mathrm{O}$ teor de proteína da maioria das espécies de pescado encontra-se em uma média de 15 a $20 \%$. Os peixes também apresentam uma quantidade significativa de todos os aminoácidos essenciais, podendo, por conseguinte, melhorar a qualidade da proteína de uma dieta mista. Além da proteína e dos aminoácidos, outros atributos nutricionais do peixe diz respeito à qualidade dos lipídeos, vitaminas e minerais disponíveis. Esse alimento possui uma procura maior em países em desenvolvimento, onde se estima que cerca de $60 \%$ da população dependa do peixe para a obtenção de mais de $30 \%$ de suas fontes de proteína animal, enquanto em países desenvolvidos quase $80 \%$ da população obtém do pescado menos de $20 \%$ de suas proteínas animais. Entretanto, com o elevado número de pesquisas evidenciando os benefícios advindos da alimentação com pescados e com o consequente aumento nos preços devido à procura, estes números vêm se alterando com grande velocidade, com o consumo de peixes assumindo importância cada vez maior no panorama do abastecimento alimentar (FAO, 2005; SAMPAIO E BRAGA, 2005).

Além de fontes de alimento e saúde, a pesca e a aquicultura são fontes de riqueza para muitos países. A geração de empregos do setor cresceu mais rapidamente que a população mundial. O setor emprega milhões de pessoas em todo o mundo, além de dar suporte aos seus meios de subsistência. Especialmente em países em desenvolvimento, a produção e o comércio de pescados podem corresponder à metade das mercadorias totais comercializadas (FAO, 2005). No Brasil, programas governamentais, agências financiadoras e órgãos de pesquisa buscam garantir a melhoria da qualidade de vida das comunidades que vivem ao redor de mananciais, orientando métodos mais eficazes de produção para aumento da empregabilidade e melhoria de suas condições socioeconômicas (BARBOSA ET. AL., 2010).

No entanto, é preciso enxergar além da economia e garantir que o bem estar humano seja compatível com o bem estar ambiental, a fim de que se consiga prosperidade sustentável a toda a população, ainda que em longo prazo. Para esse efeito, a finalidade dos países deve ser assegurar a pesca responsável e a aquicultura sustentável (FAO, 2005). Essa preocupação baseia-se na degradação do meio ambiente relacionada a algumas práticas. 
O setor de aquicultura, bem como a pesca, apresenta riscos ocupacionais e de segurança alimentar e ambiental. A pressão nos estoques naturais de pescado, oriundo da pesca extrativa, vem promovendo a extinção de várias espécies naturais, no entanto a degradação ambiental também se faz presente na prática da aquicultura. $O$ excesso de substâncias tóxicas naturais e administradas pelo homem, como pesticidas, antibióticos e poluentes orgânicos persistentes, podem representar problemas para a estabilidade do ecossistema e para muitos consumidores. Regulamentos internacionais para o setor de aquicultura são complexos e visam controlar várias práticas, como a escolha do local para cultivo, o controle da poluição, a qualidade da água e a segurança alimentar (COLE ET. AL., 2009).

\section{Produção global de pescados}

Nas últimas cinco décadas a produção mundial de pescados cresceu de forma expressiva e constante a uma taxa anual média de $3,2 \%$ ao ano, superando o crescimento da população de $1,6 \%$ ao ano, sendo a China a maior responsável pela disponibilidade mundial de peixes. Segundo a Organização das Nações Unidas para a Alimentação e a Agricultura (FAO, 2014), a produção mundial total de pescados (incluindo pesca de captura continental e marinha e aquicultura continental e marinha) cresceu de 140,7 milhões de toneladas em 2007 a 158 milhões de toneladas em 2012.

Enquanto a produção total da pesca de captura vem se mantendo constante ou até reduzindo, devido à diminuição dos estoques naturais capazes de garantir níveis biologicamente sustentáveis à exploração, a aquicultura tem apresentando um crescimento expressivo ao longo dos anos, com uma taxa média anual de 6,2\% no período de 2000 a 2012. No entanto essa taxa de crescimento apresentou-se inferior ao período de 1990 a 2000, cujo crescimento médio anual era de $9,5 \%$, podendo ser explicado por fatores como competição por recursos hídricos, disponibilidade limitada de locais de produção e custos crescentes no valor de insumos (FAO, 2014; MOURA E SILVA, LOSEKANN E HISANO, 2013).

Apesar do crescimento menor nos últimos anos, a tendência mundial da aquicultura como principal fornecedora de pescados se mantém ininterrupta. Em 2012, a aquicultura contribuiu com 42,2\% do total de peixes produzidos, superando os 13,4\% em 1990 e 25,7\% em 2000. As projeções da FAO para o período de 2012 a 2021 preveem um crescimento de $15 \%$ da produção aquícola e pesqueira sobre o nível médio estipulado para o período de 2009 a 2011, estimando uma participação da aquicultura em 52\% da produção mundial de peixes, superando a pesca de captura (FAO, 2014).

Atualmente, a aquicultura continental superou a maricultura na produção total de peixes para fins de alimentação, atingindo $63 \%$ da produção mundial de aquicultura em 2012 (FAO, 2014).

A criação de tilápia, especialmente a tilápia do Nilo, além de outras espécies de ciclídeos, é o tipo de aquicultura mais difundida em todo o mundo, estando presente em pelo menos 135 países em todos os continentes (FAO, 2014).

\section{Aquicultura no Brasil}

O Brasil apresenta inúmeras vantagens para o desenvolvimento da aquicultura em seu território, bem como para a intensificação da pesca marinha. Com mais de 6,5 milhões de hectares em lagos, reservatórios e represas, o país apresenta uma capacidade de produção superior a 700.000 toneladas de tilápia anualmente. A disponibilidade de água e terra, o clima favorável, a grande disponibilidade de insumos para ração e o baixo custo de produção são fatores que contribuem para esse crescimento. No entanto, a aquicultura no Brasil tem 
mostrado uma velocidade de crescimento muito inferior ao seu potencial. Países como Egito, Indonésia e Filipinas apresentaram um crescimento da tilapicultura mais expressivo, ainda que com menos recursos naturais disponíveis (HALWART, 2007; MPA, 2013; WATANABE ET. AL., 2002).

Em 2011, a produção nacional de pescados foi superior a 1,4 milhões de toneladas, sendo a pesca extrativa marinha a principal fonte de produção do pescado nacional, seguido pela aquicultura continental, pesca extrativa continental e aquicultura marinha. Apesar de ainda não se caracterizar como a principal fonte de produção de pescados, a aquicultura nacional apresentou um incremento de 51,2\% na produção durante o triênio 2009-2011, indicando o crescimento do setor, especialmente na aquicultura continental, cujo desenvolvimento pode estar relacionado, em parte, à ampliação de políticas públicas (MPA, 2013). A tilápia é a espécie mais produzida na aquicultura continental do país, seguida pelo tambaqui, que juntos somaram $67 \%$ de toda a produção de pescados nessa categoria em 2011 (MPA, 2013).

A intensificação da aquicultura no Brasil tem sido possibilitada por políticas públicas que apoiam projetos aquícolas de maior aproveitamento de águas disponíveis. A cessão de águas da união embasada no Decreto $\mathrm{N}^{\circ} 4.895$, de 25 de novembro de 2003, que dispõe sobre a autorização de uso de espaços físicos de corpos d'água para fins de aquicultura, pode ser considerada uma importante ferramenta para o desenvolvimento da aquicultura em tanques rede instalados dentro dos principais reservatórios do país (BRASIL, 2003; Sampaio et al., 2013). Além deste decreto, a Instrução Normativa $N^{\circ} 7$, de 2005 , especifica que até $1 \%$ da área de superfície das águas da união estará disponível para fins de aquicultura, o que corresponde a mais de 55.000 hectares (ANEEL, 2011). Tal arcabouço legal é caracterizado por estudos que contemplam diretrizes sociais, econômicas e ambientais, levando em consideração a capacidade de suporte do corpo hídrico, sendo, posteriormente, demarcadas as áreas favoráveis ao cultivo em tanques rede (SAMPAIO ET. AL., 2013).

Desde 2004, seis reservatórios foram designados pelo governo para a instalação de parques aquícolas destinados à aquicultura. Parque aquícola consiste em um espaço físico contínuo em meio aquático, delimitado, que compreende um conjunto de áreas aquícolas que, por sua vez, consistem em um espaço físico contínuo em meio aquático, delimitado, destinado a projetos de aquicultura, individuais ou coletivos (BRASIL, 2015a). A delimitação dos parques aquícolas é realizada com base em um conjunto de estudos multidisciplinares que identificam áreas ideais para se atingir a produção máxima com menor impacto ambiental. Após aprovadas em diferentes órgãos competentes, as áreas podem ser cedidas por um período de 20 anos renováveis, na modalidade não onerosa ou onerosa, de acordo com sua destinação (BUENO ET. AL., 2013).

Segundo o governo federal, a implantação de parques aquícolas em águas de domínio da união possibilitam o desenvolvimento da cadeia produtiva, a geração de empregos, a capacitação dos atores envolvidos e o aumento na produção de alimentos no país (BRASIL, $2015_{\mathrm{a}}$.

O desenvolvimento de programas nacionais com o objetivo de regularizar a atividade e orientar produtores, agentes fiscalizadores e demais envolvidos quanto aos aspectos sanitários também se faz importante para o crescimento da aquicultura no Brasil. Um exemplo é o Programa Nacional de Sanidade de Animais Aquáticos de Cultivo - Aquicultura com Sanidade, ainda não vigente, instituído através da Instrução Normativa $\mathrm{N}^{\circ} 4$, de 4 de fevereiro de 2015, que tem como finalidade promover a sustentabilidade dos sistemas de produção de animais aquáticos e a sanidade da matéria prima obtida a partir dos cultivos nacionais, definindo ações que visam à prevenção, controle e erradicação de doenças nos sistemas de produção de animais aquáticos (BRASIL, 2015b). Quando cumpridos e fiscalizados, esses programas permitem a conscientização e orientação de todos os envolvidos na cadeia 
produtiva, garantindo o crescimento da atividade de acordo com as normas internacionais e permitindo a expansão dos mercados.

Segundo Sidonio et al. (2010), apesar de todo o potencial brasileiro, a aquicultura nacional encontra-se limitada por uma série de aspectos regulatórios, técnicos e econômicos, entre eles: concessão de áreas aquícolas, obtenção de licenciamento ambiental e legislação para definição de padrões sanitários, problemas de manejo, gestão e qualificação de mão de obra e expansão dos mercados interno e externo. Esses desafios devem ser solucionados e superados para que a produção nacional de pescados alcance, de forma eficiente, o potencial máximo do país.

\section{Aquicultura em tanques rede}

A criação de peixes em tanques rede corresponde a um sistema intensivo de produção de peixes, caracterizada por uma alta concentração de animais por unidade volumétrica e pela exigência de renovação contínua da água de cultivo (BARBOSA ET. AL., 2010).

Segundo Kubtiza (2000) a criação de peixes em tanques rede é uma alternativa crescente em todo o mundo e apresenta vantagens do ponto de vista técnico, ecológico, social e econômico, quando comparado ao extrativismo e à piscicultura tradicional em tanques escavados.

Tanques rede são estruturas de tela ou rede flutuantes que abrigam os peixes de cultivo e permitem troca de água, remoção de metabólitos e fornecimento de oxigênio. Cada tanque apresenta redes com malhas cujo tamanho deve ser adequado para cada fase de cultivo (BEVERIDGE, 1984). Comedouros também são componentes fundamentais e representam estruturas colocadas no centro ou no perímetro do tanque com a função de manter o alimento dentro da área até que seja consumido, dificultando a perda promovida por ondas, vento ou pela própria movimentação dos peixes (ONO E KUBTIZA, 2003).

Como todo sistema de produção, a utilização de tanques rede para a criação de peixes possui vantagens e desvantagens. Dentre as vantagens, pode-se citar: menor variação dos parâmetros físico-químicos da água; intensificação da produção; facilidade de realocação, movimentação e despesca dos peixes; facilidade de observação dos animais, permitindo o manejo alimentar e sanitário mais adequado; possibilidade de se trabalhar em diferentes corpos d'água; e baixo investimento inicial exigido, quando comparado com outros sistemas de produção. Como desvantagens, têm-se: necessidade de fluxo constante de água através das redes para manutenção do nível adequado de oxigênio; dependência de um sistema eficaz de arraçoamento por parte do produtor com níveis balanceados de nutrientes na ração; risco de rompimento da tela levando à perda total da produção; e maior facilidade de transmissão de doenças entre os animais do tanque e através do contato com animais silvestres, como peixes nativos ou pássaros (BARBOSA ET. AL., 2010; BEVERIDGE, 1984; CONTE, 2002; ELSAYED, 2006).

Ao todo, estima-se que 40 espécies diferentes de peixes sejam produzidas em tanques, mas apenas cinco famílias (Salmonidae, Sparidae, Carangidae, Pangasiidae e Cichlidae) respondem a 90\% do total de produção (HALWART, ET. AL., 2007). No Brasil, o cultivo de tilápias vem se destacando no cenário da piscicultura, promovendo o crescimento da atividade (BARBOSA ET. AL., 2010).

A tilápia é um peixe de origem africana que vive em água doce. Foi introduzida no Brasil em 1971 em açudes do nordeste e difundiu-se por todo o país (CONTE, 2002). Por ser uma espécie precoce, de rápido crescimento, excelente desempenho em sistemas intensivos de produção e muito resistente a doenças e níveis baixos de oxigênio, a tilápia se tornou a principal espécie cultivada em tanques rede no Brasil. Como animais onívoros, em sistemas 
intensivos de produção essa espécie é alimentada com dietas formuladas com alto nível de proteínas e óleos vegetais (BARBOSA ET. AL., 2010; WATANABE ET. AL., 2002).

De acordo com Ayroza e Furlaneto (2006), a piscicultura intensiva deve ser conduzida de forma planejada, gerenciada a partir de critérios técnicos e científicos e baseada em diretrizes legais para garantir o desenvolvimento sustentável da atividade e o uso múltiplo dos recursos hídricos. Fazem parte do manejo criatório que deve ser considerado e planejado em todo sistema produtivo: avaliação de parâmetros de qualidade da água, locais adequados para a instalação dos tanques rede, avaliação da capacidade de suporte do tanque e da densidade de estocagem trabalhada, escolha das espécies e qualidade do alevino, tempo de cultivo, bem como qualidade da ração administrada e frequência de arraçoamento (ROJAS AND WADSWORTH, 2007).

Além dos aspectos produtivos, aspectos sanitários de limpeza e desinfecção de tanques e equipamentos como puçás, comedouros, baldes e barcos, bem como o controle da movimentação dos animais e de práticas como evisceração ou descarte de animais mortos, devem ser realizados dentro de um sistema de produção, visando controlar a transmissão de doenças (FRANCIS-FLOYD, 2000).

A transmissão de patógenos em animais aquáticos difere da transmissão em animais terrestres, especialmente em sistemas de tanque rede. A água funciona como um facilitador da disseminação de patógenos e da transmissão entre os membros daquela população, como animais de um mesmo tanque ou animais nativos. As formas de transmissão podem ser direta, indireta, entre fazendas e entre animais cultivados e espécies silvestres. Na produção de peixes em tanques rede é frequente a ocorrência de todas essas vias de transmissão (CORSIN ET. AL., 2009).

O confinamento de animais no interior de tanques facilita a transmissão direta de patógenos devido ao elevado contato entre os animais. A transmissão indireta também é frequente nesse sistema devido ao contato de organismos vivos, como pássaros, com os animais cultivados e devido ao contato desses animais com equipamentos e materiais utilizados sem prévia limpeza e desinfecção ou compartilhados entre diferentes unidades produtivas. A transferência de patógenos entre fazendas também é possível em casos de proximidade entre elas e segundo as taxas de troca de água entre essas unidades. Por fim, por serem instalados em reservatórios ou rios que abrigam espécies nativas de peixes, a transmissão de patógenos pode ocorrer através do contato entre animais cultivados e silvestres, em ambas as direções. Essas rotas ilustram a importância de se tomar medidas sanitárias adequadas para controlar ou minimizar a presença de patógenos nesse sistema de produção (CORSIN, ET. AL., 2009).

Sidonio et al. (2010) afirmam que, apesar do crescimento da atividade de aquicultura no Brasil e de todos os esforços dos envolvidos na cadeia produtiva, muitas empresas e produtores se deparam com a ausência de normas de biossegurança regulamentadas pelo governo e afirmam que ainda não se encontra consolidado no país um padrão sanitário bem definido para a criação de espécies de peixes em tanques rede, bem como instruções e orientações a serem seguidas com relação a manejo, densidade de estocagem, entre outros.

\section{Epidemiologia na aquicultura}

A gestão de questões de sanidade em aquicultura ainda representa um grande desafio para muitos países. Georgiadis et al. (2001), ao examinarem os problemas de gestão de risco em saúde para as principais espécies de peixes cultivadas nos Estados Unidos, revelaram que as doenças infecciosas representam o maior obstáculo para o crescimento futuro da aquicultura no país. 
Surtos de doenças causam perdas significativas na aquicultura em todo o mundo, apresentando efeitos diretos no comércio de animais aquáticos e seus produtos. Em níveis locais, a ocorrência de doenças pode causar graves impactos no sustento e na segurança alimentar de muitos pequenos produtores. Os custos atribuídos à mortalidade de peixes incluem custos com medicamentos, vacinas e perdas de produção. Além disso, animais que sobrevivem a uma infecção apresentam um crescimento mais lento e são mais susceptíveis a infecções secundárias ou a situações de estresse, como baixo nível de oxigênio (BERNOTH E HILL, 2008; GEORGIADIS ET. AL., 2001).

A ocorrência de doenças é um problema frequente em populações de animais aquáticos. Quando esses problemas ocorrem em um ambiente aquático aberto, a intervenção muitas vezes não é possível. No entanto, no caso da aquicultura, por se tratar de um ambiente mais restrito, muitos esforços se fazem possíveis no controle de doenças (Bernoth e Hill, 2008). Situações de emergência de doenças requerem a tomada de decisões rápida e eficiente para controlar, mitigar ou prevenir o problema. Essas decisões são baseadas em estudos epidemiológicos (MURRAY, 2008).

A epidemiologia veterinária pode ser definida como o estudo das doenças e de seus determinantes em populações animais, buscando aprimorar o bem estar e a saúde animal (DOHOO, ET. AL., 2003). Para alcançar esse propósito, a epidemiologia veterinária integra uma série de disciplinas, incluindo economia, estatística, produção animal e análise de risco (VOSE, 2000). O papel da epidemiologia na sanidade de animais aquáticos tornou-se claro a partir do surgimento de patógenos emergentes que rapidamente se disseminaram em sistemas intensivos de aquicultura e das interações de doenças entre animais silvestres e cultivados, que vem ganhando proporções cada vez maiores (PEELER E TAYLOR, 2011).

Apesar da metodologia epidemiológica ainda não estar amplamente difundida na sanidade de animais aquáticos, há uma conscientização crescente dos envolvidos no setor quanto à importância da atuação de epidemiologistas para o desenvolvimento de programas efetivos de controle de doenças. A interação entre epidemiologistas e especialistas tem resultado em um aprimoramento do conhecimento das causas e do gerenciamento de doenças infecciosas na aquicultura. Entre as principais ferramentas utilizadas no âmbito da saúde de animais aquáticos, têm-se: estudos de fatores de risco, análises de risco, avaliação de testes diagnósticos e estudos experimentais (GEORGIADIS ET. AL., 2001). Ainda, a vigilância de doenças constitui outra importante ferramenta a ser aplicada na área da sanidade de animais aquáticos, tendo como objetivos detectar doenças novas e exóticas, avaliar a distribuição e a frequência de doenças endêmicas e o progresso de programas de controle de doenças ou demonstrar território livre de uma ou mais doenças (OIDTMANN ET. AL., 2011).

Nos últimos anos, um grande progresso foi feito na área de vigilância em saúde de animais aquáticos com relação a diretrizes e regulamentos políticos em âmbito nacional e internacional. A convocação da Organização Mundial de Saúde Animal (OIE) para a Primeira Conferência Global em Saúde de Animais Aquáticos, em outubro de 2006, promoveu grande evolução na discussão sobre a abordagem adequada a ser realizada em casos de emergência de doenças de animais aquáticos. A publicação das normas para animais aquáticos (OIE aquatic standards), desenvolvida pela OIE, passou a fornecer as bases científicas e regras internacionalmente aceitas para o comércio de animais aquáticos e seus produtos, garantindo que os países membros se protejam da introdução de doenças em seus territórios através de medidas sanitárias justificáveis. Essas normas incluem orientações para certificação sanitária, análises de risco e planos de contingência, bem como padrões específicos para doenças. Além disso, a OIE vem realizando, em seus países membros, avaliações do desempenho dos serviços veterinários e de saúde dos animais aquáticos a partir da ferramenta PVS tools aquatic, com o objetivo de identificar pontos estratégicos para vigilância e controle (BERNOTH AND HILL, 2008; OIE, 2007). 
No Brasil, assim como em outros países, as autoridades governamentais têm buscado a regulamentação da atividade a partir da publicação de normas que visam fiscalizar a cadeia e orientar os envolvidos quanto a questões produtivas e sanitárias. Paralelamente a isso, autoridades veterinárias procuram desenvolver competências na área de sanidade de animais aquáticos, atuando de acordo com normas e regulamentos publicados.

Segundo Peeler e Taylor (2011), a falta de dados é frequentemente a principal limitação na aplicação de novas ferramentas de vigilância e modelagem de doenças. No entanto, a necessidade de ferramentas epidemiológicas para garantir a saúde dos animais aquáticos tende a crescer devido a desafios como mudanças climáticas, aumento da pressão antrópica, escassez de recursos hídricos e crescimento da aquicultura.

\section{Principais patógenos de tilápia}

Perdas decorrentes de doenças infecciosas em animais aquáticos aumentaram significativamente a partir do crescimento e intensificação da aquicultura em todos os grandes países produtores de tilápia.

Entre os principais patógenos que se destacam por causar perdas econômicas nesse tipo de sistema, têm-se o Streptococcus agalactie, Flavobacterium columnare, Francisella sp., Edwardsiella spp., Aeromonas spp. e o Iridovirus (AMAL E ZAMRI-SAAD, 2011; LEAL ET. AL., 2014).

Casos de múltiplas infecções por diferentes patógenos, como bactérias, vírus e parasitas, são comuns em sistemas de produção intensivos, especialmente aqueles praticados em tanques rede. No entanto, esse campo ainda encontra-se pouco explorado.

\section{Caracterização produtiva e sanitária de reservatórios}

A cessão de uso de águas da união para a implementação de práticas de aquicultura tem se tornado uma importante fonte de produção aquícola no Brasil. Sua política dá-se nos termos do Decreto $\mathrm{n}^{\mathbf{0}}$ 4.895, de 25 de novembro de 2003, e da Instrução Normativa Interministerial $\mathrm{n}^{\mathrm{o}}$ 06, de 31 de maio de 2004, instrumentos legais que regem a matéria no Brasil (BRASIL, 2014a).

Esses instrumentos estabelecem as normas complementares para a autorização de uso dos espaços físicos em corpos d'água de domínio da União para fins de aquicultura, e dá outras providências. Dentre as informações solicitadas, destacam-se: documentação de regularidade fiscal da pessoa física ou jurídica, projeto de criação a ser desenvolvido, mapa de localização com as coordenadas da área requerida e espécies a serem cultivadas (BRASIL, $2014_{\mathrm{a}}$ ).

Para a regularização dos empreendimentos de aquicultura, órgãos do meio ambiente exigem a formalização dos procedimentos técnicos administrativos por meio do licenciamento ambiental. A obtenção da licença ambiental e o atendimento às condicionantes possibilita aos produtores o acesso ao crédito, assim como contribui para o controle e a prevenção de impactos ambientais, a fim de assegurar a sustentabilidade e segurança da operação dos empreendimentos (BRASIL, $2014_{\mathrm{a}}$ ).

No entanto, apesar da atividade de aquicultura em reservatórios ser facilitada por políticas que a regularizam e apresentar um crescimento cada vez mais expressivo no país, observa-se ausência de atenção a aspectos sanitários nesse sistema de produção, em diferentes regiões.

É imprescindível a definição de medidas de biossegurança para a mitigação dos fatores de risco existentes nesse sistema de produção, buscando superar os entraves existentes para o desenvolvimento da atividade devido ao surgimento de doenças. 
Para a definição de medidas de biossegurança se faz necessária a caracterização dos sistemas produtivos e de seus riscos sanitários, fornecendo informações relevantes que viabilizam a adoção de políticas públicas para a regularização da atividade.

Baseado nisso, a caracterização do reservatório de Três Marias, especialmente no município de Morada Nova de Minas contribui para o avanço do conhecimento na área permitindo a aplicação de ferramentas epidemiológicas que garantam a identificação dos principais riscos sanitários e a mitigação dos fatores de risco identificados.

No município de Morada Nova de Minas, a Companhia de Desenvolvimento dos Vales do São Francisco e Parnaíba (CODEVASF) implantou, em novembro de 2001, a primeira unidade demonstrativa de produção de tilápia em tanque rede. Essa iniciativa, em um primeiro momento, permitiu a união de alguns pequenos produtores através de uma cooperativa. Em 2006 foi anunciada ainda a construção da primeira unidade de beneficiamento do pescado no município, o que motivou o aumento de investimentos no setor (BRASIL, 2015 b).

Em 2015 a produção de peixes no lago Três Marias atingiu cerca de 6.807 toneladas de pescado ano, com uma receita bruta de peixe inatura (fresco) superior a trinta e sete milhões de reais. Os municípios que compõem o entorno do reservatório somam, aproximadamente, 5.931 tanques-rede de diferentes dimensões, distribuídos em 71 pisciculturas, com 160 piscicultores atuando na área e gerando uma média de 369 empregos diretos e 1.480 empregos indiretos (BRASIL, 2015b).

A caracterização de aspectos produtivos e sanitários do cultivo de peixes em reservatório e do perfil socioeconômico dos produtores é de extrema relevância para o conhecimento das características individuais e locais que devem ser levadas em conta ao desenvolver políticas públicas focadas na prevenção e na certificação sanitária de organismos aquáticos, bem como ao planejar um sistema de vigilância de doenças. 


\section{OBJETIVO}

Caracterizar as formas de produção de tilápia em tanque rede no reservatório de Três Marias, Minas Gerais, focando em aspectos produtivos e sanitários. 


\section{REFERÊNCIAS BIBLIOGRÁFICAS}

AMAL, M.N.A., ZAMRI-SAAD, M.. Streptococcosis in tilapia (Oreochro- mis niloticus): a review. Pertanika J. Trop. Agric. Sci., 34, p. 195-206, 2011.

ANEEL. Relatorios Anuais. Agência Nacional de Energia Eletrica. Brasılia, 2011.

AYROZA, D.M.M.R.; FURLANETO, F.P.B; AYROZA, L.M.S. Regularização dos projetos de tanques-rede em águas públicas continentais de domínio da união no Estado de São Paulo. Boletim Técnico do Instituto de Pesca, São Paulo, v.36, 2006.

BARBOSA, A.C.A., MOURA, E.V. DE, SANTOS, R.V. Cultivo de tilápias em gaiolas. Circuito d. ed. EMPARN, Rio Grande do Norte - Natal, , 2010.

BEVERIDGE, M. C. M. Cage and pen fish farm: carryng capacity models and environmental impact. Rome: FAO, 131 p, 1984.

BERNOTH, E.M., HILL, B.J. Changing trends in managing aquatic animal disease emergencies. Rev. Sci. Tech. 27, 13-29, 2008.

BRASIL. Decreto no 4.895, de 25 de novembro de 2003. Dispõe sobre a autorização de uso de espaços físicos de corpos d'água de domínio da União para fins de aquicultura, e dá outras providências. Diário Oficial da República Federativa do Brasil, Brasília, 26 nov, 2003.

BRASIL. Ministério da Pesca e Aquicultura-Parques Aquícolas, 2015a. Disponível em: $<$ http://www.

mpa.gov.br/index.php/aquiculturampa/aguas-da-uniao/parques aquicolas/parquesaquicolascontinentais> (Acesso em Setembro 2015).

BRASIL. IN no 4 , de 4 de fevereiro. Institui o programa nacional de sanidade de animais aquáticos de cultivo - "Aquicultura com sanidade". Ministério da Pesca e Aquicultura. DOU seção 1. P. 47-52, 2015b. Disponível em: <http://www.mpa.gov.br> (Acesso em Janeiro 2016).

BUENO, G.W., OSTRENSKY, A., CANZI, C., DE MATOS, F.T., ROUBACH, R. Implementation of aquaculture parks in Federal Government waters in Brazil. Rev. Aquaculture, 1-12, doi:10.1111/raq.12045, 2013.

CARVALHO, E.D., CAMARGO, A.L.S., ZANATTA, A.S. Desempenho produtivo da tilápia do nilo em tanques-rede numa represa pública: modelo empírico de classificação. Ciência Rural, 40, 1616-1622. doi:10.1590/S0103-84782010000700021, 2010.

COLE, D.W., COLE, R., GAYDOS, S.J., GRAY, J., HYLAND, G., JACQUES, M.L., POWELL DUNFORD, N., SAWHNEY, C., AU, W.W. Aquaculture: environmental, toxicological, and health issues. Int. J. Hyg. Environ. Health, 212, 369-377, 2009.

CONTE, F. Stress and the welfare of cultured fish. Appl. Anim. Behav. Sci. 86, 205-223. doi:10.1016/j.applanim.2004.02.003, 2004.

CONTE, L. Produtividade e Economicidade da Tilapicultura em Gaiolas na Região 
Sudoeste do Estado de São Paulo: Estudos de Casos 73, 2002.

CORSIN, F., GEORGIADIS, M., HAMMELL, K. L., HILL, B. Guide for Aquatic Animal Health Surveillance. Published by The World Organisation for Animal Health. 126 p, 2009.

DOHOO, I.R., MARTIN, W., STRYHN, H. Veterinary Epidemiologic Research. Transcontinental Prince Edward Island, Canada, p. 706, 2003.

EL-SAYED, A.- F.M. Intensive Culture. In: Abdel-Fattah M. El-Sayed (Ed.) Tilapia Culture, London, Cap.5, p.70-94, 2006.

ELTHOLTH, M., FORNACE, K., GRACE, D., RUSHTON, J., HÄSLER, B.

Characterisation of production, marketing and consumption patterns of farmed tilapia in the Nile Delta of Egypt. Food Policy, 51, 131-143. doi:10.1016/j.foodpol.2015.01.002, 2015.

FAO. Fisheries and Aquaculture topics. Nutricional elements os fish. Topics Fact Sheets. Text by Lahsen Ababouch. In: FAO fisheries and Aquaculture Departement [online]. Rome. Updated 27 May 2005. Disponível em: <http://www.fao.org/fishery/topic/12319/en> (Acesso em Janeiro 2016).

FAO. The state of world fisheries and aquaculture. Food and Agriculture Oraganization of the United Nations. doi:92-5-105177-1, 2014.

FRANCIS-FLOYD, R. Sanitation Practices for Aquaculture Facilities. Sanit. Pract. Aquac. Facil. 1-5. doi:VM87, 2000.

GARCIA, F., ROMERA, D.M., GOZI, K.S., ONAKA, E.M., FONSECA, F.S., SCHALCH, S.H.C., CANDEIRA, P.G., GUERRA, L.O.M., CARMO, F.J., CARNEIRO, D.J., MARTINS, M.I.E.G., PORTELLA, M.C. Stocking density of Nile tilapia in cages placed in a hydroelectric reservoir. Aquaculture, 410-411, 51-56.

doi:10.1016/j.aquaculture.2013.06.010, 2013.

GEORGIADIS, M.P., GARDNER, I. A., HEDRICK, R.P. The role of epidemiology in the prevention, diagnosis, and control of infectious diseases of fish. Prev. Vet. Med. 48, 287302. doi:10.1016/S0167-5877(00)00202-6, 2001.

HALWART, M., SOTO, D., ARTHUR, J.R. (Eds.). Cage aquaculture-regional reviews and global overview. FAO Fisheries Technical Paper, 498. FAO, Roma (241 pp.). 22, 2007.

KUBITZA, F. Qualidade de água, sistemas, planejamento da produção, manejo nutricional e alimentar e sanidade. Panorama da Aqüicultura, v.10, n.59, p. 44-53, 2000.

LAZZARI, R., BALDISSEROTTO, B., DE NITROGÊNIO, E., FÓSFORO, E., RESUMO, E.P. Nitrogen and Phosphorus Waste in Fish Farming. In: LAZZARI e BALDISSEROTTO B. Inst. Pesca 34, 591-600, 2008.

LEONARDO, A.F.G., BACCARIN, A.E. Desempenho produtivo de tilápias do Nilo criadas em tanques rede em represa rural no Vale do Ribeira. Bol. Indústria Anim. 71, 256-261. doi:10.17523/bia.v71n3p256, 2014. 
MPA. Ministério da Pesca e Aquicultura. Produção Pesqueira e Aquicola 60, 2013. MOURA E SILVA, M.S.G..; LOSEKANN, M.E.; HISANO, H. Aquicultura: manejo e aproveitamento de efluentes. Empresa Brasileira de Pesquisa Agropecuária. Embrapa Meio Ambiente. Jagariúna, SP, 2013.

MURRAY, A.G. Existing and potential use of models in the control and prevention of disease emergencies affecting aquatic animals. Rev. sci. tech. Off. int. Epiz. 27, 211-228, 2008.

OIDTMANN, B.C., CRANE, C.N., THRUSH, M. A., HILL, B.J., PEELER, E.J. Ranking freshwater fish farms for the risk of pathogen introduction and spread. Prev. Vet. Med. 102, 329-340. doi:10.1016/j.prevetmed.2011.07.016, 2011.

OIE, World Organisation for Animal Health - The OIE Global Conference on Aquatic Animal Health. Proc. of a global conference organised by the World Organisation for Animal Health - OIE (B. Dodet in collaboration with the Scientific and Technical Department of the OIE, eds), 9-12 October 2006, Bergen, Norway. Dev. Biol., 129, Karger, Basel, 194 pp, 2007.

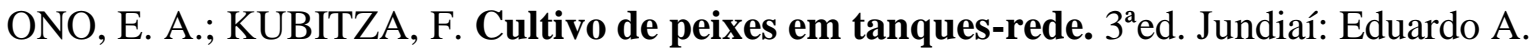
Ono. 112p, 2003.

PEELER, E.J., TAYLOR, N.G. The application of epidemiology in aquatic animal health -opportunities and challenges. Vet. Res. 42, 94. doi:10.1186/1297-9716-42-94, 2011.

ROJAS, A., WADSWORTH, S. A review of cage aquaculture : Latin America and the Caribbean. Cage Aquac. - Reg. Rev. Glob. Overv. 77-100, 2007.

SAMPAIO, F.G., LOSEKANN, M.E., JOSÉ, A., LUIZ, B., NEVES, M.C., FRASCÁSCORVO, C.M.D. Monitoramento e gestão ambiental da piscicultura em tanques-rede em reservatórios. Inf. Agropecuário, 34, 1-11, 2013.

SAMPAIO, J.M.C., BRAGA, L.G.T. Cultivo de tilápia em tanques-rede na barragem do Ribeirão de Saloméa - Floresta Azul - Bahia. Rev. Bras. Saúde Prod. An. 6, 42-52, 2005.

SEBRAE, Serviço Brasileiro de Apoio às Micro e Pequenas Empresas. Criação de tilápias em tanques-redes, 2007. Disponível em:

<http://www.biblioteca.sebrae.com.br/bds/bds.nsf/7227d4d9d30ab6cc832573a9006df4bc/\$fil e/nt0003737a.pdf> (Acesso em Janeiro, 2016).

SIDONIO, L., CAVALCANTI, I., CAPANEMA, L., MORCH, R., MAGALHÃES, G., LIMA, J., BURNS, V., JOSÉ, A., JÚNIOR, A., MUNGIOLI, R. Panorama da aquicultura no Brasil: desafios e oportunidades. BNDES Setorial 35, 421-463, 2010.

SUBASINGHE, R.P. Epidemiological approach to aquatic animal health management: Opportunities and challenges for developing countries to increase aquatic production through aquaculture. Prev. Vet. Med. 67, 117-124. doi:10.1016/j.prevetmed.2004.11.004, 2005.

TORNIMBENE, B., CHHIM, V., SORN, S., DREW, T.W., GUITIAN, J. Knowledge, attitudes and practices of Cambodian swine producers in relation to porcine reproductive and respiratory syndrome (PRRS). Prev. Vet. Med. 116, 252-67. 
doi:10.1016/j.prevetmed.2013.12.009, 2014.

VOSE, D.. Risk Analysis-A Quantitative Guide. John Wiley \& Sons, Chichester, 2000. WATANABE, W.O., LOSORDO, T.M., FITZSIMMONS, K., HANLEY, F. Tilapia Production Systems in the Americas: Technological Advances, Trends, and Challenges. Rev. Fish. Sci. 10, 465-498. doi:10.1080/20026491051758, 2002. 


\title{
CAPÍtULO II
}

\section{Caracterização de aspectos produtivos e sanitários da criação de tilápia em tanque rede no reservatório de Três Marias, Minas Gerais}

\author{
Productive and sanitary aspects related to tilapia production in the Tres Marias reservoir
}

\begin{abstract}
RESUMO
O Brasil é um dos países com maior potencial pesqueiro do mundo, no entanto ainda ocupa o $17^{\circ}$ lugar no ranking da produção aquícola, indicando o subaproveitamento de seus recursos naturais. A estratégia mais eficiente para garantir um ritmo anual de crescimento é a adoção de sistemas de produção mais competitivos e sustentáveis, incluindo a aquicultura em tanques-rede instalados dentro dos principais reservatórios do país, de acordo com políticas públicas que regulamentam a cessão de águas da União para fins de aquicultura. O presente estudo objetivou caracterizar os padrões de produção de tilápia em tanque rede no reservatório de Três Marias, com enfoque em aspectos produtivos e sanitários. Para tanto, realizou-se um estudo descritivo no reservatório de Três Marias, Minas Gerais, a partir dos dados coletados por meio de questionário estruturado aplicado durante o mês de maio de 2015. O questionário foi aplicado a todos os 32 produtores de peixes em tanques-rede do município de Morada Nova de Minas, que compõe o entorno do reservatório de Três Marias. Como resultado, observou-se que a atividade de aquicultura no município é exclusiva para apenas $17 \%$ dos produtores, que relataram não possuir outra fonte de renda. Pouco menos da metade dos produtores apresentam mão de obra do tipo familiar. Independentemente do tipo de mão de obra, predominam propriedades com até três funcionários envolvidos no manejo dos animais $(81,3 \%)$ e apenas duas propriedades recebem assistência técnica regular. A tilápia é a única espécie produzida comercialmente no município de Morada Nova de Minas, tendo como principal destino de venda frigoríficos sem inspeção sanitária (67\%). Aspectos sanitários são considerados pela maioria dos produtores, que adotam medidas de limpeza de tanques e utensílios, não compartilhamento de equipamentos com outras unidades produtivas e descarte adequado dos animais mortos e moribundos em valas de enterrio (76\%). Conforme a percepção dos produtores, as principais causas de mortalidade de peixes no reservatório são: temperatura e nível de água (72\%), qualidade do alevino (31\%) e manejo alimentar incorreto $(24 \%)$. Entre os principais entraves relatados pelos piscicultores, destacam-se a dificuldade em obter o licenciamento ambiental (59\%), o alto custo da ração (34\%) e o baixo nível de água nos reservatórios (31\%), apenas 6,9\% indicou a presença de doenças. Diante disso, verifica-se a necessidade de planejamento estratégico envolvendo as partes interessadas para melhor estruturação da cadeia produtiva. Torna-se indispensável o desenvolvimento de ferramentas para a tomada de decisões que possibilitem o crescimento ordenado e sustentável da aquicultura.
\end{abstract}

Palavras-chave: Aquicultura; Tanques-rede; Caracterização; Reservatório; Tilápia. 


\begin{abstract}
Brazil has a huge potential for aquaculture; however, it is only the $17^{\text {th }}$ largest producer according to aquaculture rankings, indicating an underutilization of its resources. The most efficient strategy to ensure a high annual growth rate is the adoption of more competitive and sustainable production systems, such as fish farming in net cages installed within the key reservoirs of the country, and following public policies that regulate the assignment of water from the Union to aquaculture production. The present study aimed to characterize tilapia production patterns in net cages at the Três Marias reservoir, focusing on the production and sanitary aspects. The data were collected through a structured questionnaire during May 2015. The study involved all the 32 fish farmers, who use net cages, in the municipality Morada Nova de Minas, which comprises the surroundings of Três Marias reservoir. Aquaculture was the sole income-generating activity for only $17 \%$ of the farmers in this municipality. Less than half of the farmers had a workforce that comprised their family members only. Irrespective of the type of workforce, having up to three members of staff for the management of animals was the predominant trend (81.3\%), and only two farms received regular technical assistance. Tilapia was the only species commercially produced in the municipality of Morada Nova de Minas, and were sold to local slaughterhouses, most of which did not undergo official sanitary inspections (67\%). Sanitation practices were adopted by a majority of the farmers, who cleaned their cages and tools, did not share equipment with other farms, and appropriately discarded dead or dying animals in ditches (76\%). According to the farmers' perception, the primary causes of fish mortality in the reservoir were water temperature and water level (72\%), fingerling quality (31\%), and improper feed management (24\%). The difficulties most frequently reported by the fish farmers were: difficulty in getting environmental licences (59\%), high cost of animal feed (34\%), and low water levels in the reservoir (31\%), whereas only $6.9 \%$ stated disease losses were a major concern. In conclusion, this emerging production chain is mostly comprised of small fish farmers with low levels of production technology with limited support of health and extension services. The sustainable development of fish production in public waters needs to be in line with environmental concerns and will depend on identification of cost-effective solutions for the health and production bottlenecks reported in this baseline survey.
\end{abstract}

Keywords: aquaculture; net cages; characterization; public reservoir; tilapia. 


\section{INTRODUÇÃO}

Nos últimos anos, a produção mundial de pescados se consolidou como um setor de grande importância econômica, tanto pela produção de alimentos, quanto pela geração de empregos e renda. A aquicultura é considerada o setor de produção animal que apresenta o ritmo de crescimento mais acelerado, devido em parte à intensa exploração dos recursos pesqueiros naturais (Carvalho et al., 2010). Em 2012, a atividade foi responsável por aproximadamente $42 \%$ da produção mundial de pescado e, atualmente, fornece quase a metade de todo o pescado para a alimentação humana (FAO, 2014).

Entretanto, conjuntamente a essa expansão, surgem limitações inerentes a qualquer sistema de produção animal. No caso da produção de pescados, essas limitações estão relacionadas em grande parte a questões ambientais de competição por recursos hídricos e comprometimento da qualidade da água, além de questões como a necessidade de investimento e melhoria em infraestrutura, obediência a políticas e regulamentos e aperfeiçoamento de tecnologias que garantam melhoramento genético, qualidade do produto final e gestão de riscos à saúde animal (Georgiadis et al., 2001; Lazzari e Baldisserotto, 2008).

Por esse motivo, o aproveitamento de recursos hídricos por meio da utilização de águas públicas para o cultivo em tanque rede de diversas espécies é um ponto chave para garantir sistemas de produção cada vez mais competitivos e sustentáveis. Essa prática vem crescendo em vários países, tais como China, Indonésia e Brasil (Sampaio et al., 2013).

Apesar de ocupar o $17^{\circ}$ lugar no ranking de maior produtor mundial de aquicultura, indicando o subaproveitamento de recursos naturais, o cultivo de tilápia no Brasil apresenta o crescimento mais acelerado do mundo (FAO, 2014; MPA, 2013; Watanabe et al., 2002). Esse cenário tem se consolidado ainda por meio da aquicultura em tanques-rede instalados dentro dos principais reservatórios do país, de acordo com políticas públicas que regulamentam a cessão de águas da união para fins de aquicultura (BRASIL, 2004). Tais políticas facilitaram $\mathrm{o}$ acesso de muitos produtores à atividade e, consequentemente, o aumento da produção de pescado no país.

Dentre as espécies de peixe, a tilápia é a mais cultivada, especialmente em sistemas de produção em tanque rede, representando aproximadamente $47 \%$ da produção total de pescados no país, seguida pelo tambaqui e tambacu (MPA, 2013).

No Brasil, existem parques aquícolas instalados em diversos reservatórios, entre eles o reservatório de Três Marias, em Minas Gerais, cujas atividades de aquicultura iniciaram-se em 2001, com o apoio da Companhia de Desenvolvimento dos Vales do São Francisco e do Parnaíba (CODEVASF). Três Marias possui produção anual estimada em 6,6 mil toneladas, distribuída em sete municípios que circundam o reservatório, gerando recursos e empregos para a população. O uso desses reservatórios de forma planejada garante o aproveitamento múltiplo das águas, evitando impactos ambientais indesejáveis (BRASIL, 2012; BRASIL, $2015_{\mathrm{a}}$ ).

Conjuntamente à expansão da prática de aquicultura em tanques-rede, surgem problemas decorrentes da ocorrência e disseminação de doenças em animais aquáticos, que constitui a principal barreira para o crescimento da atividade em diversas partes do mundo. A movimentação de animais aquáticos vivos e seus produtos e o cultivo de espécies exóticas aceleraram a disseminação e a invasão de patógenos em novas populações e áreas geográficas, gerando perdas de produção e problemas de segurança alimentar. Por esse motivo, a implementação de práticas de biossegurança em todas as fases de um sistema de produção constitui uma das ferramentas mais efetivas para a prevenção e o controle de doenças . No entanto, a escassez de orientações e regulamentações para produtores e profissionais e a ausência de estratégias nacionais para o controle da introdução e 
disseminação de doenças de animais aquáticos ainda representam um importante obstáculo para o crescimento da aquicultura nacional.

A lacuna de dados disponíveis acerca da situação atual e do funcionamento da atividade no Brasil constitui outro importante desafio para o desenvolvimento da aquicultura no país que, apesar de crescente, revela níveis de crescimento inferiores aos anos anteriores. Não há relatos específicos que permitam traçar o perfil dos produtores, o manejo realizado nesse sistema de produção, bem como o verdadeiro potencial do setor.

Diante disso, o melhor conhecimento desse sistema possibilitaria o desenvolvimento de políticas públicas para impulsionar a atividade, o apoio do setor privado para intensificar o mercado e o interesse de instituições de pesquisa para implementar tecnologias avançadas de melhoramento genético, produção e controle de enfermidades, reduzindo também as perdas relacionadas a manejo e aspectos sanitários.

Essas informações permitem ainda identificar pontos críticos de controle e sugerir alternativas para superar os principais desafios encontrados ao longo da cadeia (Eltholth et al., 2015).

O presente estudo objetivou caracterizar os padrões de produção de tilápia em tanque rede no reservatório de Três Marias, voltado para aspectos produtivos e sanitários.

\section{MATERIAIS E MÉTODOS}

Para a caracterização do reservatório de Três Marias, foi realizado um estudo descritivo a partir dos dados coletados por meio de entrevista semi-estruturada aos produtores, durante o mês de maio de 2015. A lista de pisciculturas foi fornecida pela CODEVASF.

\section{1.Área estudada}

A entrevista foi realizada em todos os produtores de peixes em tanques-rede do município de Morada Nova de Minas, que compõe o entorno do reservatório de Três Marias e representa o principal município produtor, seguido por Felixlândia.

Em 2015, Morada Nova de Minas apresentava 32 produtores de tilápia distribuídos em pontos distintos do reservatório, representando $43,4 \%$ do total de unidades produtivas existentes nos sete municípios produtores que circundam o reservatório.

O município de Morada Nova de Minas foi escolhido devido a sua alta representatividade e importância para o setor da aquicultura em tanque rede no reservatório de Três Marias. Além disso, por ser o único município do entorno a abrigar o escritório da CODEVASF, pode-se contar com o apoio logístico e operacional para a aplicação do questionário a todos os produtores, devidamente cadastrados no sistema.

O mapa 1 ilustra o reservatório de Três Marias com os sete municípios que o circundam, indicando o número de pisciculturas por município. As 32 pisciculturas visitadas encontram-se demarcadas a partir dos dados georreferenciados. 
Mapa 1. Localização das pisciculturas visitadas no município de Morada Nova de Minas.

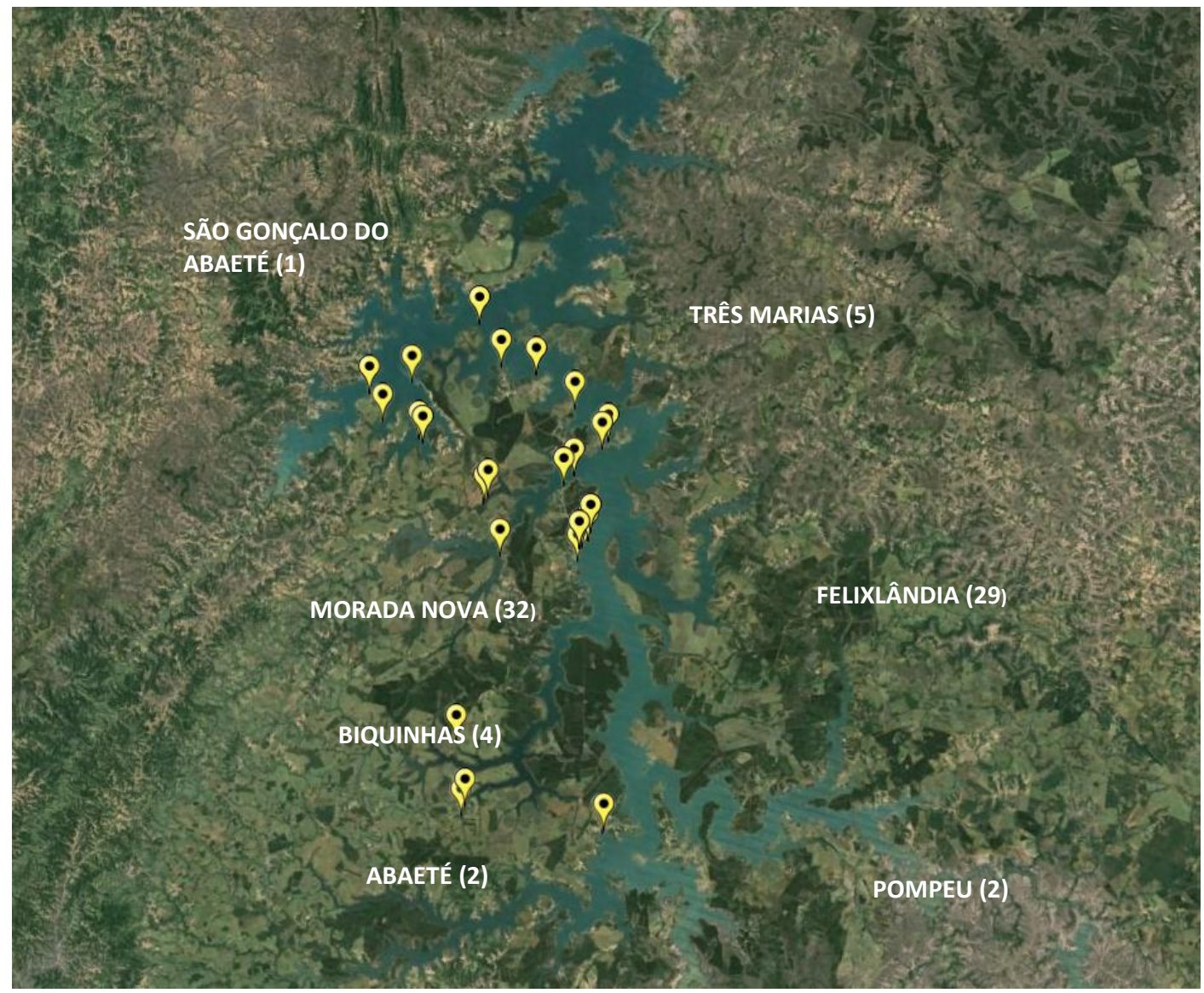

\subsection{Entrevista semi-estruturada}

A entrevista foi desenvolvida a partir de ampla revisão bibliográfica para abranger as questões mais relevantes da produção de peixes em tanques rede, complementada por uma visita ao reservatório, durante a qual foram discutidos os temas pertinentes à pesquisa com os principais atores sociais do arranjo produtivo local, bem como foram visitadas várias unidades produtoras.

Após finalizada a primeira versão, as questões selecionadas para a entrevista semiestruturada passaram por uma etapa de validação, sendo aplicadas em oito propriedades produtoras de tilápia em tanques-rede do reservatório de Serra da Mesa, em Goiás. Isso permitiu que questões não aplicáveis à realidade estudada fossem reformuladas e problemas de interpretação corrigidos.

\subsection{Coleta de dados}

A entrevista foi realizada por dois entrevistadores devidamente treinados e o acesso às propriedades foi possível em virtude do apoio logístico de funcionários da CODEVASF.

Os dados foram coletados em um período de uma semana, durante o mês de maio de 2015, em todas as 32 propriedades. As questões eram feitas preferencialmente ao produtor, entretanto, na ausência deste, os funcionários ficavam responsáveis por responder os questionamentos. 


\subsection{Análise dos dados}

Utilizou-se o software Stata® versão 12 para tratamento estatístico dos dados por meio de análise descritiva básica e análise univariada entre as variáveis de interesse, utilizando o teste do qui-quadrado. Por se tratar de um censo, as análises realizadas e as associações avaliadas revelam o verdadeiro parâmetro daquela população, à época da coleta de dados, não sendo necessários cálculos de intervalos de confiança.

\section{RESULTADOS E DISCUSSÃO}

\subsection{Características gerais}

As pisciculturas do município de Morada Nova de Minas apresentam características semelhantes com relação aos tanques utilizados no sistema de produção. Predominam propriedades que utilizam tanques com dimensões de 2 × 2 × 1,5 m $\left(6 \mathrm{~m}^{3}\right)$, presentes em $94 \%$ das pisciculturas.

Conforme observado no gráfico abaixo (gráfico 1), que revela a distribuição de número de tanques-rede por propriedade no município, a menor piscicultura possui 8 tanques, enquanto a maior apresenta 405 tanques, e pode ser considerado um outlier. De acordo com o valor dos quartis, observamos que $50 \%$ das pisciculturas possuem até 80 tanques e apenas 25\% mais de 163 tanques. Esses dados indicam a grande variação existente no município com relação à quantidade de tanques por propriedade.

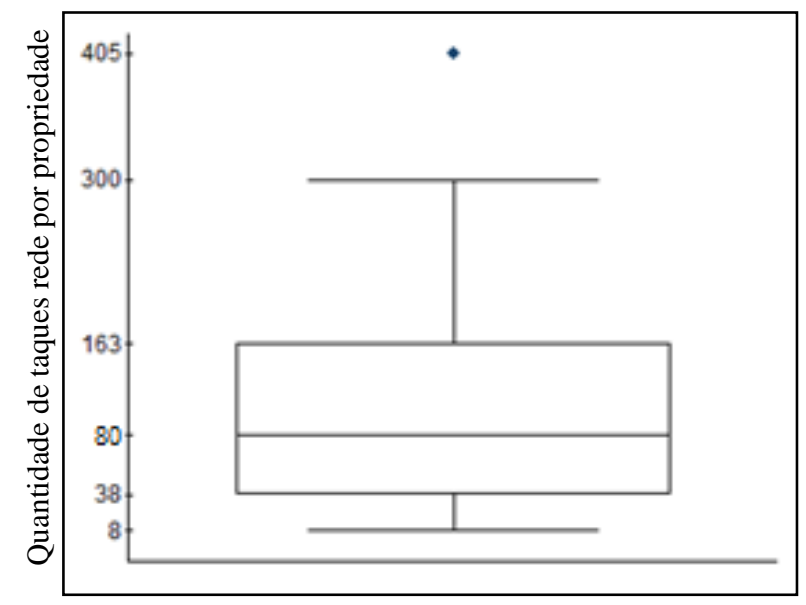

Gráfico 1. Quantidade de tanques-rede por propriedade no município de Morada Nova de Minas, MG.

Pouco mais da metade dos produtores do município (56,3\%) apresentam mão de obra contratada, sendo o restante apenas familiar, ou seja, as pessoas envolvidas no manejo dos animais são membros da própria família.

Independentemente do tipo de mão de obra, predominam propriedades com até três pessoas envolvidas nas atividades $(81,3 \%)$. Das propriedades com mais de três pessoas $(18,7 \%), 67 \%$ destas apresentam mão de obra do tipo contratada. Essas propriedades são maiores e mais desenvolvidas (tabela 1 ). 
Tabela 1. Frequência do tipo de mão de obra por número de pessoas envolvidas no manejo dos animais nas pisciculturas em tanque rede do município de Morada Nova de Minas, MG.

\begin{tabular}{ccccccc}
\hline & \multicolumn{2}{c}{ Familiar } & \multicolumn{2}{c}{ Contratada } & \multicolumn{2}{c}{ Total } \\
\cline { 2 - 7 } & $\mathbf{n}$ & $\mathbf{\%}$ & $\mathbf{n}$ & $\mathbf{\%}$ & $\mathbf{n}$ & \% \\
\hline Até 3 & 12 & 46,2 & 14 & 53,8 & 26 & 100 \\
Mais de 3 & 2 & 33,3 & 4 & 66,7 & 6 & 100 \\
\hline Total & 14 & 43,7 & 18 & 56,3 & 32 & 100 \\
\hline
\end{tabular}

Vinte e quatro por cento das pisciculturas possuem funcionários que auxiliam no manejo de animais de outras pisciculturas, eventualmente.

Apenas duas propriedades recebem assistência técnica regular, sendo uma delas uma cooperativa. A assistência técnica em ambas é prestada por um médico veterinário particular. Essa prática é incomum no restante das propriedades. Uma terceira propriedade relatou recorrer à assistência técnica apenas em surtos de mortalidade.

A aquicultura se apresenta como atividade remuneratória exclusiva para $17 \%$ dos produtores do município, enquanto que $83 \%$ informaram possuir outros meios remuneratórios.

Observa-se que produtores que apresentam a atividade de aquicultura como meio remuneratório exclusivo possuem, em geral, propriedades com mão de obra predominantemente familiar $(60 \%)$ e até três pessoas envolvidas no manejo produtivo dos animais (tabelas 2 e 3 ).

Tabela 2. Frequência de tipo de mão de obra por realização de outras atividades remuneradas nas pisciculturas em tanque rede do município de Morada Nova de Minas, MG.

\begin{tabular}{|c|c|c|c|c|c|c|}
\hline \multirow{3}{*}{$\begin{array}{l}\text { Realização de outras } \\
\text { atividades remuneradas }\end{array}$} & \multicolumn{6}{|c|}{ Tipo de mão de obra } \\
\hline & \multicolumn{2}{|c|}{ Familiar } & \multicolumn{2}{|c|}{ Contratada } & \multicolumn{2}{|c|}{ Total } \\
\hline & $\mathbf{n}$ & $\%$ & $\mathbf{n}$ & $\%$ & $\mathrm{n}$ & $\%$ \\
\hline Não & 3 & 60 & 2 & 40 & 5 & 100 \\
\hline Sim & 9 & 37,5 & 15 & 62,5 & 24 & 100 \\
\hline Total & 12 & 41 & 17 & 59 & $29^{*}$ & 100 \\
\hline
\end{tabular}

Tabela 3. Frequência de número de funcionários por realização de outras atividades remuneradas nas pisciculturas em tanque rede do município de Morada Nova de Minas, MG.

\begin{tabular}{|c|c|c|c|c|c|c|}
\hline \multirow{3}{*}{$\begin{array}{l}\text { Realização de outras } \\
\text { atividades remuneradas }\end{array}$} & \multicolumn{6}{|c|}{ Pessoas envolvidas no manejo } \\
\hline & \multicolumn{2}{|c|}{ Até 3} & \multicolumn{2}{|c|}{ Mais de 3} & \multicolumn{2}{|c|}{ Total } \\
\hline & $\mathbf{n}$ & $\%$ & $\mathrm{n}$ & $\%$ & $n$ & $\%$ \\
\hline Não & 5 & 100 & 0 & 0 & 5 & 100 \\
\hline Sim & 18 & 75 & 6 & 25 & 24 & 100 \\
\hline Total & 23 & 79 & 6 & 21 & $29^{*}$ & 100 \\
\hline
\end{tabular}

\subsection{Dados de produção}

A tilápia é a única espécie produzida comercialmente no município de Morada Nova de Minas. Os piscicultores adquirem os alevinos por meio de duas larviculturas presentes no município.

Novos alevinos são introduzidos mensalmente nas propriedades, uma vez que essas apresentam um sistema de produção contínuo. A quantidade de alevinos introduzidos por mês é muito variável entre as unidades produtivas. O gráfico 2 apresenta a correlação entre quantidade de alevinos introduzidos mensalmente e a quantidade de tanques por propriedade. 


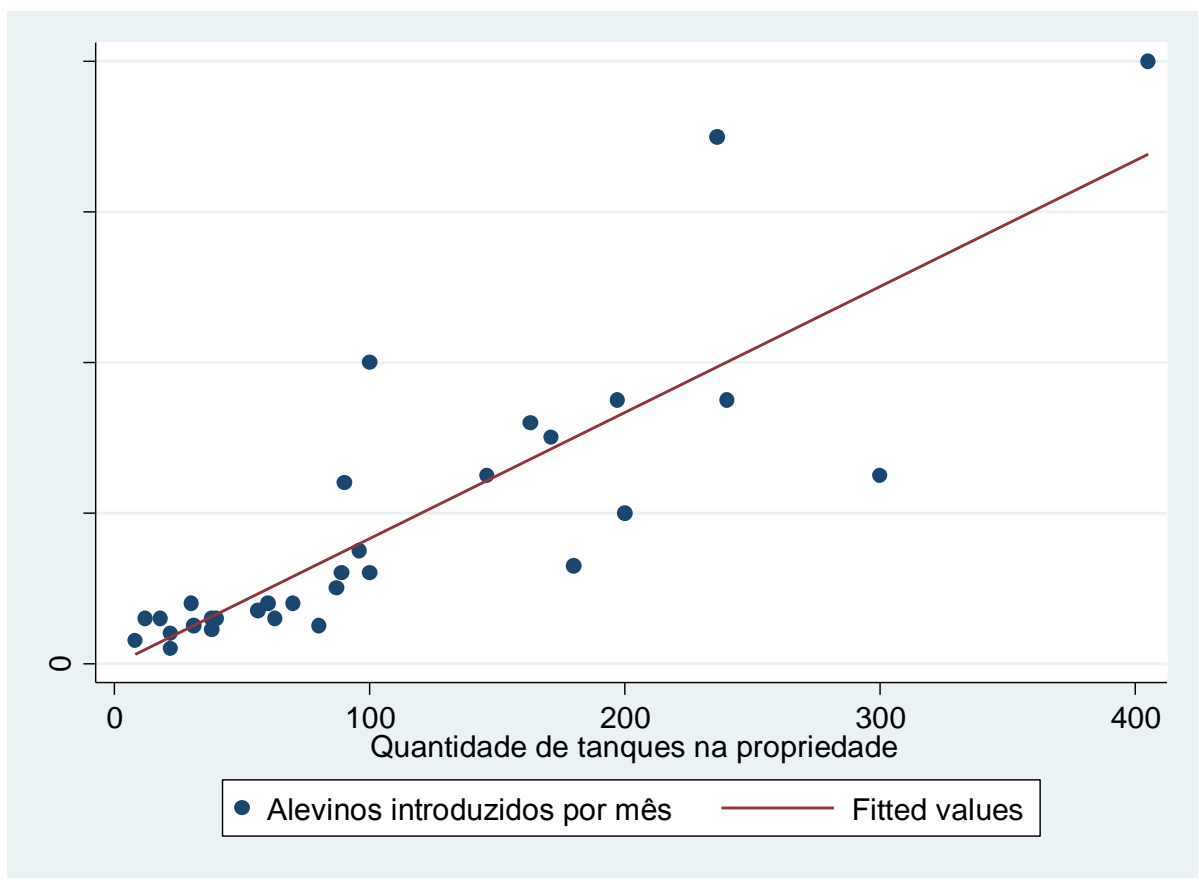

Gráfico 2. Quantidade de alevinos introduzidos por mês por quantidade de tanques por propriedade nas pisciculturas em tanque rede no município de Morada Nova de Minas, MG.

Observa-se uma correlação positiva entre a quantidade de alevinos introduzidos mensalmente e a quantidade de tanques por propriedade. A menor propriedade com relação à quantidade de tanques é também a propriedade que insere a menor quantidade de alevinos por mês, com o mesmo acontecendo para a maior propriedade. No entanto, devido ao pequeno número de observações, essa tendência não apresenta uma representação tão clara.

Entre as propriedades que possuem tanques com dimensões de $6 \mathrm{~m}^{3}(94 \%$ das pisciculturas), $75 \%$ utilizam densidade de até 600 peixes por tanque. Ainda assim, não foi observada grande variação nas densidades utilizadas pelos produtores do município, uma vez que os valores variaram de 450 a 650 peixes por tanque.

A densidade média de animais por tanque encontrada nas propriedades de Morada Nova de Minas mostra-se inferior à densidade encontrada por Zago (2012) no reservatório de Água Vermelha (São Paulo), de 800 tilápias por tanque rede na fase de terminação. De acordo com Garcia et al. (2013), essa densidade permite uma boa conversão alimentar, além de representar menores problemas de doenças e mortalidades no tanque.

A alimentação dos animais é proveniente de ração comercial em 97\% das propriedades. Apenas uma propriedade relatou o uso de ração de fabricação própria. A utilização constante de outra substância adicionada à alimentação dos animais foi relatada por 10,3\% dos produtores. As substâncias acrescidas à ração estão descritas no Gráfico 3. 


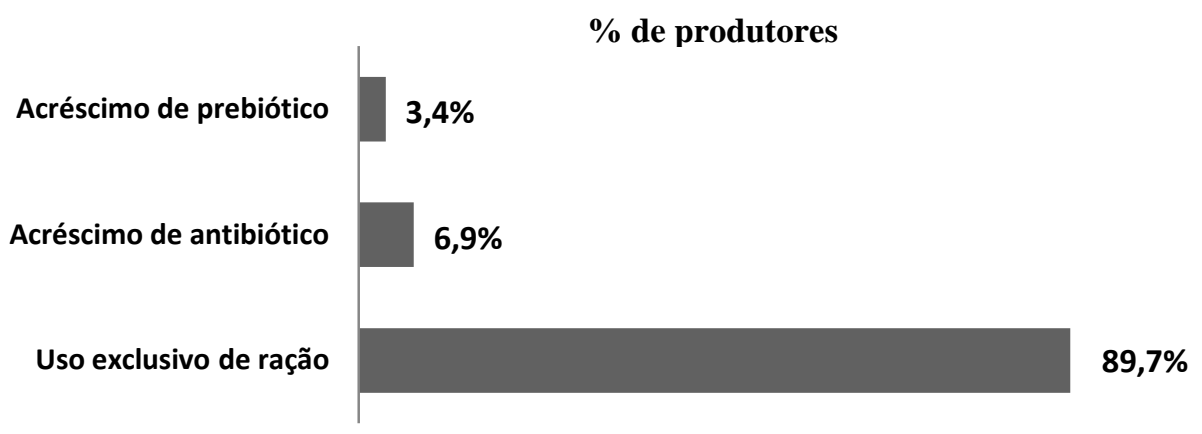

Gráfico 3. Frequência de relatos de utilização de substâncias acrescidas à ração nas pisciculturas em tanque rede do município de Morada Nova de Minas, MG.

Duas propriedades informaram que realizam o uso constante de antibiótico acrescido à ração durante o berçário $(6,9 \%)$. O uso de prebiótico foi relatado por apenas um produtor. Nenhum piscicultor informou a utilização de vitamina para a suplementação dos animais.

A utilização de ração comercial por $97 \%$ dos produtores de Morada Nova de Minas vai de encontro ao revelado por Zago (2012), no reservatório de Água Vermelha (São Paulo), em que os produtores relataram o uso apenas de ração comercial extrusada na alimentação das tilápias e por Eltholth et al. (2015), no Egito, que revelou que o uso de ração comercial é feita por $94 \%$ dos produtores, enquanto apenas $5 \%$ utiliza ração produzida na própria unidade.

De acordo com Barbosa et al. (2010), rações não comerciais ou artesanais não são economicamente viáveis, pois geralmente possuem baixa estabilidade no ambiente e composição nutricional inadequada, ocasionando perdas de produção.

O gráfico 4 revela a distribuição da duração do ciclo de produção por piscicultura. Observa-se que um ciclo de produção apresenta variação de cinco a nove meses entre as pisciculturas do município de Morada Nova de Minas, com 75\% dos produtores trabalhando com ciclos de até sete meses.

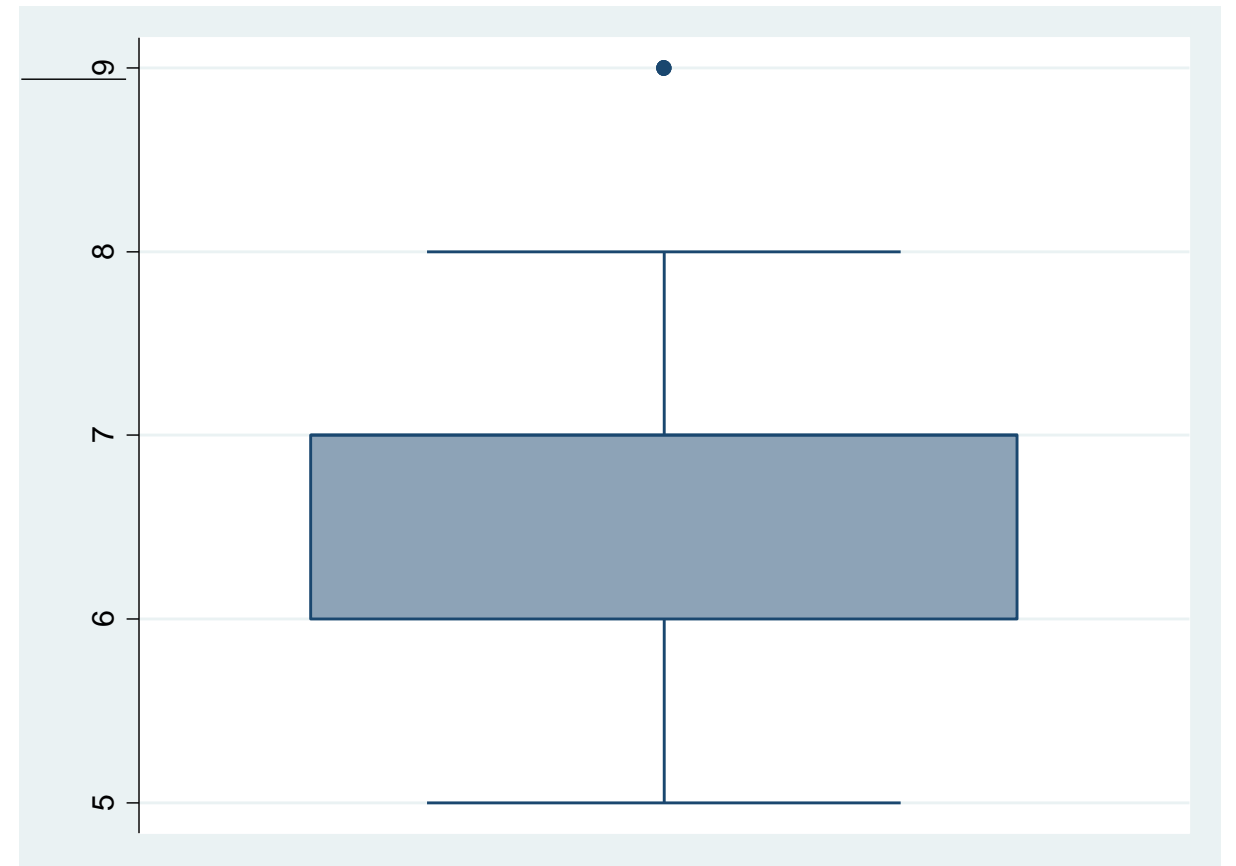

Gráfico 4. Duração do ciclo de produção por piscicultura em tanque rede no município de Morada Nova de Minas, MG. 
A duração do ciclo de produção mostra-se associado com o peso: produtores que trabalham com ciclos de produção mais curtos, em sua maioria (89\%), despescam os animais com até um quilograma de peso, bem como produtores que trabalham com ciclos exatos de sete meses $(79 \%)$. Produtores que trabalham com ciclos mais longos, superiores a sete meses, despescam animais maiores, com mais de um quilograma (tabela 4).

Tabela 4. Frequência de categorias de duração de ciclo de produção por peso das tilápias na despesca nas pisciculturas em tanque rede do município de Morada Nova de Minas, MG.

\begin{tabular}{ccccccc}
\hline \multirow{2}{*}{ Duração do ciclo } & \multicolumn{7}{c}{ Peso das tilápias na despesca } \\
\cline { 2 - 7 } & \multicolumn{2}{c}{ Até 1 Kg } & \multicolumn{2}{c}{ Mais de 1 Kg } & \multicolumn{1}{c}{ Total } \\
\cline { 2 - 7 } & $\mathbf{n}$ & $\mathbf{\%}$ & $\mathbf{n}$ & $\mathbf{\%}$ & $\mathbf{n}$ & $\mathbf{\%}$ \\
\hline Menos de 7 meses & 8 & 88,9 & 1 & 11,1 & 9 & 100 \\
$\mathbf{7}$ meses & 11 & 78,6 & 3 & 21,4 & 14 & 100 \\
Mais de 7 meses & 0 & 0 & 9 & 100 & 9 & 100 \\
\hline Total & 19 & 59,4 & 13 & 40,6 & 32 & 100 \\
\hline
\end{tabular}

A partir da tabela 4 pode-se inferir que o tamanho do ciclo deve estar associado ao peso final desejado de acordo com as exigências do mercado, não estando associado necessariamente a problemas de manejo ou problemas sanitários.

Com relação aos procedimentos de classificação e repicagem, $72 \%$ dos produtores informaram realizá-los uma vez por ciclo (gráfico 5). Esse manejo se mostra uma prática necessária para o acompanhamento do desenvolvimento do animal e para avaliação da densidade de estocagem mais adequada para o seu desempenho (Conte, 2002). No entanto, alguns produtores se queixam do alto índice de perdas decorrentes do estresse provocado por esse procedimento e optam por não realizá-lo.

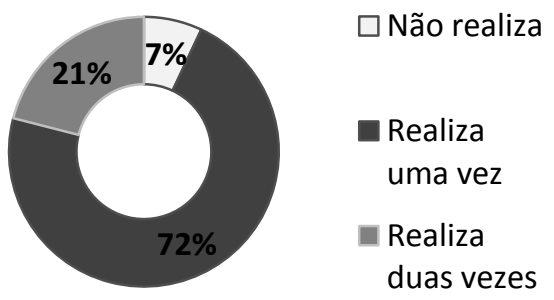

Gráfico 5. Frequência de realização de procedimentos de classificação e repicagem no manejo produtivo das pisciculturas no município de Morada Nova de Minas, MG.

Produtores que apresentam duração de ciclo de produção mais curta e, consequentemente, despescam o animal com menos de um quilograma, em geral não realizam procedimentos de classificação e repicagem dos animais. Esses valores corroboram com os resultados obtidos por Carvalho et al. (2010) que observaram que lotes heterogêneos de pescado, não submetidos a processos de classificação e repicagem, alcançam peso muito inferior quando comparados a lotes homogeneamente classificados em um mesmo período de tempo.

A destinação das tilápias despescadas encontra-se descrita no gráfico 6. 
\% de produtores

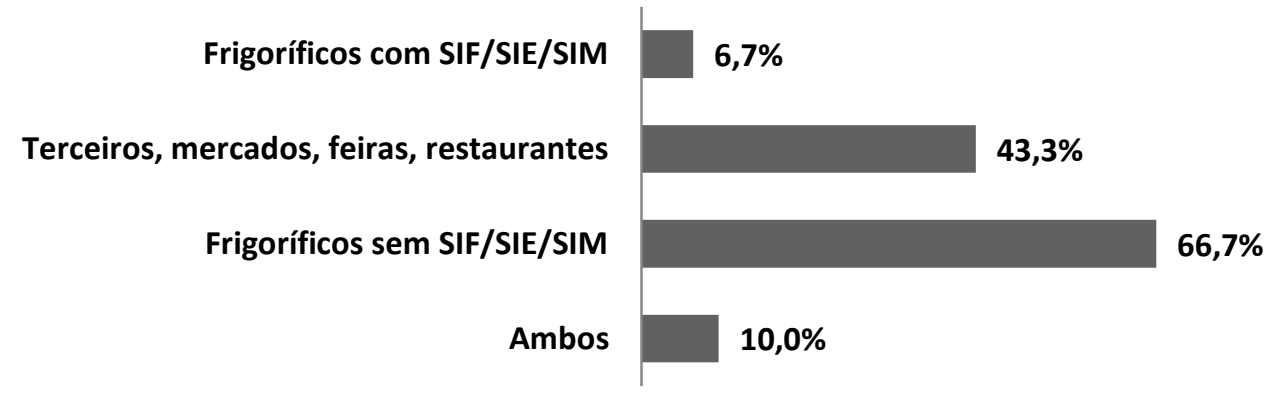

Gráfico 6. Frequência de produtores de peixe em tanque-rede de acordo com o destino das tilápias despescadas no município de Morada Nova de Minas, MG.

Devido ao fato de o município de Morada Nova de Minas possuir apenas um frigorífico registrado com sistema de inspeção oficial e com baixa capacidade de processamento para a produção da região, apenas duas propriedades, sendo uma a cooperativa, apresentam essa destinação. Na maioria dos casos, os peixes são vendidos para frigoríficos que ainda não possuem inspeção oficial $(66,7 \%)$, diretamente para mercados, feiras e restaurantes $(45 \%)$, ou ambos $(10 \%)$.

A prática de evisceração na propriedade, relatada por $31 \%$ dos produtores do município, mostrou-se relacionada com o destino de venda dos animais despescados (gráfico 7).

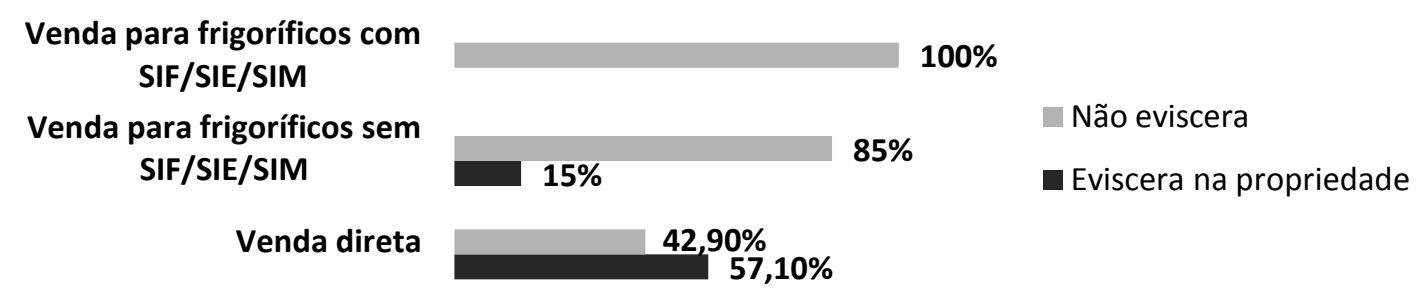

Gráfico 7. Frequência de evisceração de tilápias nas propriedades segundo destino de venda nas pisciculturas em tanque rede do município de Morada Nova de Minas, MG.

Mais da metade dos produtores que informaram realizar venda direta para terceiros ou mercados $(57 \%)$ realizam evisceração na propriedade. Sabe-se que para esse tipo de venda, o produto é destinado diretamente para o consumidor final, exigindo do produtor que a limpeza e evisceração sejam feitas ainda na propriedade. Apenas $15 \%$ dos que destinam seu produto para frigoríficos sem SIF relataram a prática. Nenhum produtor que realiza venda para o frigorífico com SIF informou eviscerar o peixe na propriedade. Ademais, observou-se que os produtores que realizam evisceração dentro de sua unidade produtiva não apresentam infraestrutura adequada, do ponto de vista sanitário e ambiental, para a realização da prática.

A prática de evisceração na propriedade revela um risco sanitário para a produção de peixes. De acordo com Oidtmann et al. (2011), o processamento de peixes, quando realizado no local de produção, pode representar um risco para a introdução e disseminação de doenças.

\subsection{Dados sanitários}

Com relação à limpeza de tanques e utensílios, 97\% dos produtores realizam a limpeza dos tanques, predominantemente por meio de lavagem e secagem completa sob o sol, sempre ao final de cada ciclo. Setenta e seis por cento informaram se preocupar também com a limpeza de utensílios, como puçá, barcos, baldes e alimentadores. 
Francis-Floyd (2000) enfatiza a importância dos procedimentos de higienização de tanques e de qualquer equipamento que entre em contato com o processo produtivo, seja por meio de desinfecção química ou procedimento de secagem completa em contato direto com a luz solar, para reduzir o potencial de transmissão de doenças.

Todos os produtores informaram que seus equipamentos de manejo são de uso exclusivo da propriedade, não sendo compartilhados. Além disso, os produtores informaram não trocar ou movimentar os animais entre unidades produtivas. No entanto, $17 \%$ deles afirmaram ser uma prática comum em suas propriedades movimentar animais entre tanques e lotes diferentes, ainda que fora do período de classificação, em situações de tanques danificados, problemas de mortalidade elevada em tanque específico ou baixo crescimento.

A prática de observação dos sinais clínicos indicativos de doenças dentro dos tanques foi relatada em $97 \%$ das propriedades. No entanto, produtores e funcionários afirmaram não possuírem treinamento formal para o reconhecimento de doenças. $\mathrm{O}$ gráfico 8 apresenta os principais sinais clínicos relatados pelos entrevistados.

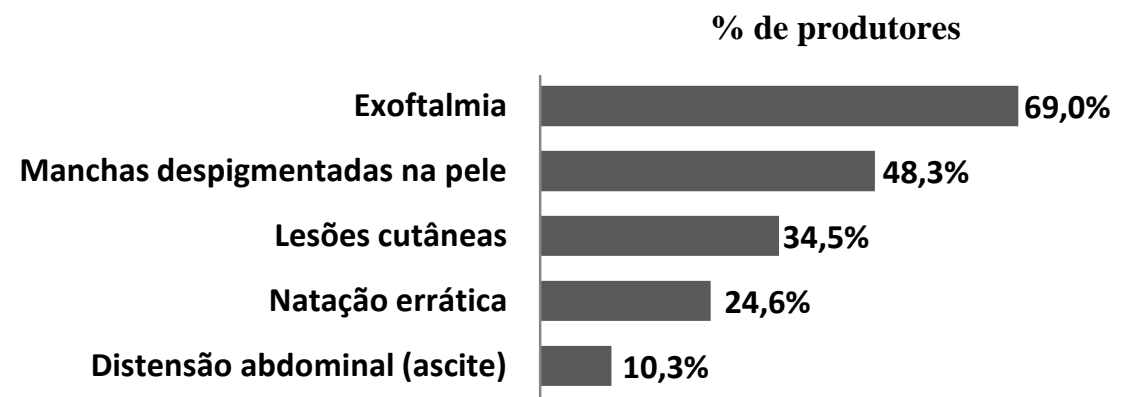

Gráfico 8. Frequência de sinais clínicos mais observados nas tilápias cultivadas no reservatório no município de Morada Nova de Minas, MG.

A observação dos principais sinais clínicos indicativos de doenças dentro dos tanques é uma prática relevante a ser realizada nas propriedades, uma vez que indicadores visuais podem servir como alerta para problemas iminentes.

Em casos de doenças ou taxas elevadas de mortalidade, $26 \%$ dos produtores relataram não realizar nenhum tratamento. Entre aqueles produtores que informaram tomar atitudes específicas, 52\% relataram fazer uso de antibióticos seguindo as recomendações do fabricante. Os antibióticos utilizados em maior frequência são: enrofloxacina, terramicina, florfenicol e oxitetraciclina. Os demais procedimentos realizados são relatados na tabela 5 .

Tabela 5. Frequência de realização de procedimentos em casos de doença ou mortalidade em tilápias nas pisciculturas em tanque rede do município de Morada Nova de Minas, MG.

\begin{tabular}{ll}
\hline Procedimento em caso de doenças & \% de produtores \\
\hline Tratamento com antibiótico & 51,6 \\
Interrupção na alimentação & 35,5 \\
Tratamento com sal & 29,0 \\
Tratamento com permanganate de potássio & 16,1 \\
Contato com assistência técnica & 6,5 \\
Envio de amostras para teste diagnóstico & 3,2 \\
\hline
\end{tabular}

O uso de medicamentos em casos de doenças ou surtos de mortalidade nas propriedades de Morada Nova de Minas vão de encontro ao descrito por Eltholth et al. (2015) com $66,7 \%$ dos produtores relatando o uso de antibiótico. Segundo Conte (2004), o uso 
frequente e excessivo de medicamentos é indicativo de exposição contínua dos animais a agentes patogênicos e a fatores causadores de estresse.

Com relação ao destino dado aos animais mortos, a prática mais relatada foi o descarte adequado em valas para enterrio (76\%). No entanto, práticas inadequadas como descarte no próprio terreno ou na represa e como alimento para outros animais também foram relatadas (gráfico 9).

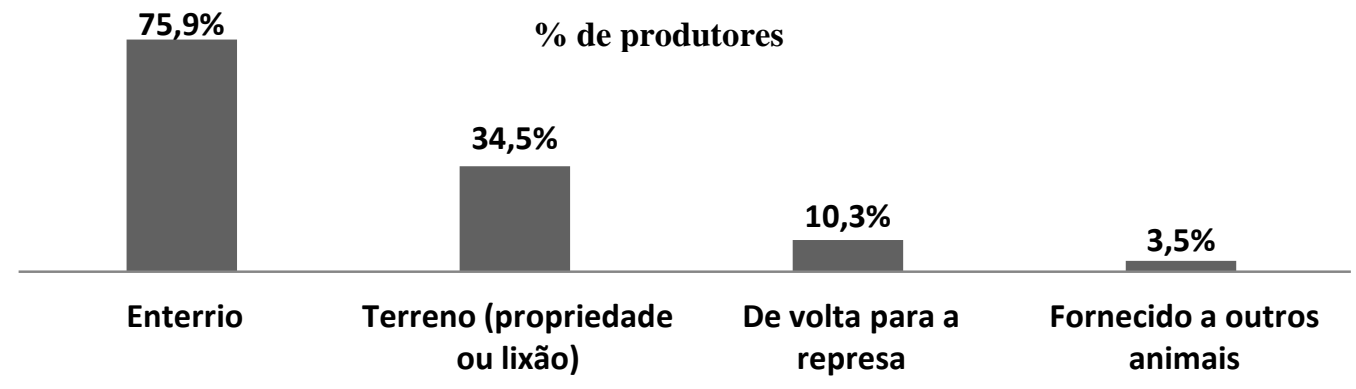

Gráfico 9. Frequência do destino dado aos animais mortos nas pisciculturas em tanque rede do município de Morada Nova de Minas, MG.

O procedimento de descarte em valas para enterrio, descrito pela maioria dos produtores, atende às definições da Instrução Normativa $\mathrm{n}^{\circ} 4$, de 4 de fevereiro de 2015 , que estabelece que as destinações adequadas para animais mortos ou moribundos são: enterrio ou compostagem, incineração, digestão ácida ou alcalina, recolhimento por empresa especializada ou tratamento em estabelecimento com serviço oficial de inspeção $\left(\mathrm{BRASIL}_{\mathrm{b}}\right.$, 2015).

A introdução de patógenos resulta de falhas nas medidas sanitárias tomadas dentro do sistema de produção, como limpeza e desinfecção inadequada de tanques e equipamentos, compartilhamento de equipamentos entre as instalações, uso de roupas e botas contaminadas por funcionários que atuam em diferentes propriedades, transmissão por aves ou outros predadores que se movimentam entre as unidades (Conte, 2004; Klontz, 1993; Oidtmann et al., 2011).

Oidtmann et al. (2011) sugere ainda outras fontes de introdução de patógenos, como introdução de alevinos já doentes, proximidade entre unidades produtivas, manipulação de peixes mortos no local de produção e uso de ração não processada para alimentação dos animais. Esses fatores refletem a importância da aplicação de medidas adequadas de manejo e biossegurança durante todo o processo produtivo.

\subsection{Parâmetros da água}

Entre os parâmetros de avaliação da qualidade da água, apenas a medição de temperatura foi descrita, sendo realizada por $82,8 \%$ dos produtores. Nenhum outro parâmetro foi relatado.

Para a maioria dos produtores (90\%), a qualidade da água no reservatório é satisfatória e não há nenhum fator que a comprometa. Os demais produtores se queixam da presença de resíduos agrícolas que são lançados no reservatório e comprometem a produtividade e a saúde dos animais.

Observou-se que produtores que se queixam de contaminação da água por resíduos agrícolas, em sua maioria (67\%), nunca mudaram de local de produção, podendo esse ser um fator de confusão, uma vez que a produção de tilápia durante um longo período em uma mesma localidade gera resíduos naturais que se acumulam no fundo do reservatório, o que também compromete a qualidade da água (tabela 6). No entanto, essa associação não é 
suficiente para concluir que os problemas de qualidade relatados por esses produtores se dão em função da permanência dos tanques em uma mesma localidade.

Tabela 6. Frequência de relatos de problemas de qualidade da água por mudança de local de produção de produtores de peixe em tanque rede no município de Morada Nova de Minas, MG.

\begin{tabular}{|c|c|c|c|c|c|c|}
\hline \multirow{3}{*}{$\begin{array}{c}\text { Problemas de qualidade } \\
\text { da água }\end{array}$} & \multicolumn{6}{|c|}{ Mudança de local de produção } \\
\hline & \multicolumn{2}{|c|}{ Não } & \multicolumn{2}{|c|}{ Sim } & \multicolumn{2}{|c|}{ Total } \\
\hline & $\mathbf{n}$ & $\%$ & $\mathbf{n}$ & $\%$ & $\mathbf{n}$ & $\%$ \\
\hline Não & 11 & 47,8 & 12 & 52,2 & 23 & 100 \\
\hline Sim & 4 & 66,7 & 2 & 33,3 & 6 & 100 \\
\hline Total & 15 & 51,7 & 14 & 48,3 & $29^{*}$ & 100 \\
\hline
\end{tabular}

Quarenta e oito por cento dos produtores da região relataram já terem mudado o local de produção para uma área geograficamente distinta. Destacaram questões ambientais, como o baixo nível de água e a presença de aguapés, que prejudicam a oxigenação dos tanques, como pontos cruciais para a mudança.

\subsection{Categorização em tamanhos de propriedade}

No geral, o manejo dos animais não apresenta grande diferença entre as pisciculturas da região, apesar da grande variação com relação à quantidade de tanques por propriedade e quantidade de alevinos introduzidos mensalmente. No entanto, algumas das variáveis avaliadas apresentaram padrões de ocorrência diferentes e relevantes entre as pisciculturas, ao serem cruzadas com a quantidade de tanques-rede.

Por esse motivo, foi realizada uma categorização das propriedades com relação a tamanho, considerando apenas a variável quantidade de tanques-rede por propriedade, uma vez que a maioria das pisciculturas trabalha com tanques de mesma dimensão. Além disso, a variável apresenta correlação positiva com a quantidade de alevinos introduzidos por mês em cada propriedade.

Após as simulações necessárias, optou-se por trabalhar com duas classificações de tamanho de propriedade: menores e maiores, devido ao número reduzido de observações. $\mathrm{O}$ ponto de corte foi definido a partir da análise descritiva dos dados e do conhecimento da realidade da região. A quantidade de tanques-rede foi categorizada em: propriedades menores, com até 80 tanques e propriedades maiores com mais de 80 tanques, com o ponto de corte representando $50 \%$ das observações. A categorização em propriedades menores e maiores é aplicável apenas à realidade do município de Morada Nova de Minas, podendo não ser adequada e não representar a realidade de outros municípios e reservatórios.

A variável "tipo de mão de obra nas pisciculturas" apresentou relação com o tamanho da propriedade (tabela 7).

Tabela 7. Frequência do tipo de mão de obra por tamanho de propriedade nas pisciculturas em tanque rede do município de Morada Nova de Minas, MG.

\begin{tabular}{ccccccc}
\hline \multirow{2}{*}{$\begin{array}{c}\text { Tamanho de } \\
\text { propriedade }\end{array}$} & \multicolumn{2}{c}{ Tipo de mão de obra } \\
\cline { 2 - 7 } & $\mathbf{n}$ & $\mathbf{\%}$ & $\mathbf{n}$ & $\mathbf{\%}$ & $\mathbf{n}$ & Total \\
\cline { 2 - 7 } & 10 & 62,5 & 6 & 37,5 & 16 & 100 \\
Menor & 4 & 25 & 12 & 75 & 16 & 100 \\
Maior & 14 & 43,7 & 18 & 56,3 & 32 & 100 \\
\hline Total & & & &
\end{tabular}

Propriedades menores, em sua maioria $(62,5 \%)$, apresentam mão de obra familiar, provavelmente por se tratarem de sistemas de produção de menor investimento. Entre as propriedades grandes, com mais de 80 tanques, $75 \%$ apresentam mão de obra do tipo 
contratada. Além disso, as duas únicas propriedades que recebem assistência técnica são consideradas pisciculturas maiores. Essas informações revelam o impacto de aspectos socioeconômicos na atividade.

A duração do ciclo de produção também apresentou diferença entre propriedades menores e maiores. Entre as pisciculturas menores, mais de $80 \%$ trabalham com ciclos de, no mínimo, sete meses, enquanto que propriedades maiores tendem a trabalhar com ciclos mais curtos. Mais de $80 \%$ das grandes propriedades trabalham com ciclos de duração máxima de sete meses (tabela 8).

Tabela 8. Frequência de duração do ciclo de produção por tamanho de propriedade nas pisciculturas em tanque rede do município de Morada Nova de Minas, MG.

\begin{tabular}{|c|c|c|c|c|c|c|c|c|}
\hline \multirow{3}{*}{$\begin{array}{l}\text { Tamanho de } \\
\text { propriedade }\end{array}$} & \multicolumn{7}{|c|}{ Peso das tilápias na despesca } & \\
\hline & \multicolumn{2}{|c|}{ Menos de 7 meses } & \multicolumn{2}{|c|}{7 meses } & \multicolumn{2}{|c|}{ Mais de 7 meses } & \multicolumn{2}{|c|}{ Total } \\
\hline & $\mathbf{n}$ & $\%$ & $\mathbf{n}$ & $\%$ & $\mathbf{n}$ & $\%$ & n & $\%$ \\
\hline Menor & 3 & 18,8 & 6 & 37,5 & 7 & 43,7 & 16 & 100 \\
\hline Maior & 6 & 37,5 & 8 & 50 & 2 & 12,5 & 16 & 100 \\
\hline Total & 9 & 28,1 & 14 & 43,8 & 9 & 28,1 & 32 & 100 \\
\hline
\end{tabular}

Por utilizar ciclos de produção mais longos, superiores a sete meses, piscicultores menores tendem a trabalhar com animais mais pesados na despesca, com peso superior a um quilograma, enquanto produtores maiores trabalham, majoritariamente, com ciclos mais curtos e, consequentemente, animais com peso inferior a um quilograma.

As pisciculturas do município apresentaram diferenças quanto ao destino de venda do produto final, conforme evidenciado no gráfico 10.

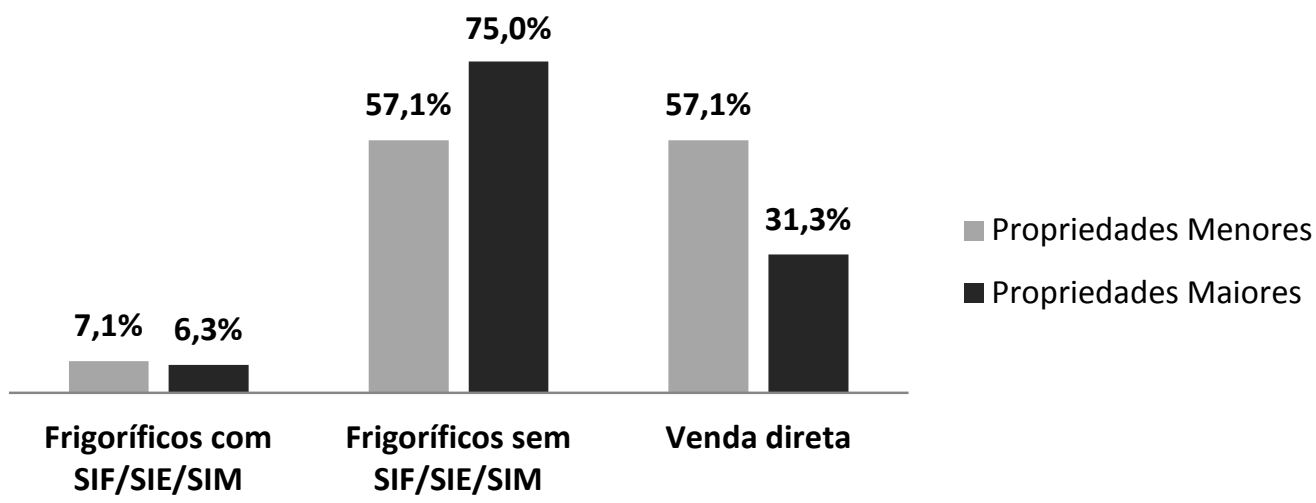

Gráfico 10. Destino de venda do produto final por tamanho de propriedade nas pisciculturas em tanque rede do município de Morada Nova de Minas, MG.

Não foram observadas diferenças entre as propriedades quanto ao destino para frigoríficos com inspeção oficial. Considerando as pisciculturas menores, não houve diferença quanto ao destino das vendas para frigoríficos sem serviço oficial de inspeção $(57,1 \%)$ e para venda direta $(57,1 \%)$, em mercados, feiras e restaurantes. Entre produtores maiores, $75 \%$ realizam vendas para os frigoríficos presentes na região. Pode-se constatar, no entanto, que entre os produtores que realizam venda direta predominam pisciculturas menores. No entanto, não é possível afirmar se essa é a razão pela qual esses produtores trabalham com ciclos mais longos para obter animais de peso superior.

Com relação aos aspectos sanitários, encontrou-se, em propriedades menores, maior frequência de produtores que não se preocupam com questões sanitárias de limpeza dos utensílios e equipamentos, quando comparadas às propriedades maiores. Além disso, a 
frequência de limpeza, quando presente, é maior em propriedades grandes em comparação com as pequenas.

A prática adequada de enterrio para destinação de peixes mortos foi relatada em 93,3\% das propriedades maiores e em 57,1\% das propriedades menores (gráfico 11). Práticas inadequadas de descarte no reservatório ou descarte para outros animais foram relatadas em maior frequência em propriedades pequenas. Informações reais a respeito do descarte dos animais mortos podem também, em algumas situações, ser omitidas pelo produtor que possui conhecimento da forma mais adequada de realizá-lo, mas não o pratica.

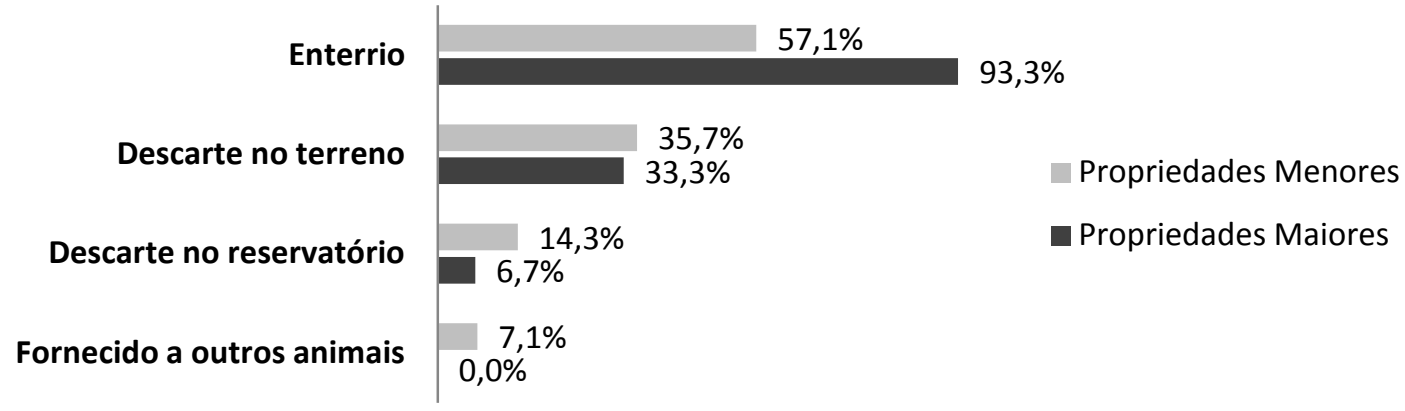

Gráfico 11. Destino dado aos animais mortos segundo tamanho de propriedade nas pisciculturas do município de Morada Nova de Minas, MG.

A questão de avaliação de parâmetros da água, como a temperatura, também apresentou diferenças entre os produtores (tabela 9).

Tabela 9. Frequência de avaliação da temperatura por tamanho de propriedade nas pisciculturas do município de Morada Nova de Minas, MG.

\begin{tabular}{cccc}
\hline \multirow{2}{*}{$\begin{array}{c}\text { Frequência de avaliação } \\
\text { da temperatura }\end{array}$} & Menor & Mamanho de propriedade & Total \\
\cline { 2 - 4 } & $\boldsymbol{\%}$ & $\boldsymbol{\%}$ & $\%$ \\
\hline Diária & 57,1 & 80 & 69 \\
Semanal & 0 & 13,3 & 7 \\
Mensal & 0 & 6,7 & 3,4 \\
Por demanda & 7,2 & 0 & 3,4 \\
Não avalia & 35,7 & 0 & 17,2 \\
\hline Total & 100 & 100 & 100 \\
\hline
\end{tabular}

Entre as propriedades que não avaliam a temperatura encontram-se apenas propriedades pequenas, que revelaram não possuírem termômetro na propriedade. Ainda, propriedades maiores tendem a avaliar a temperatura da água com uma frequência maior que propriedades menores.

\subsection{Percepção dos produtores}

Perguntou-se a opinião dos produtores quanto aos períodos e fases mais críticos para a produção de tilápia em tanques-rede, com relação à ocorrência de doenças e mortalidades. Para 69\% dos produtores, as maiores perdas se dão no período quente em animais de engorda/terminação, seguidos de perdas de alevinos em temperaturas mais baixas, relatado por $46 \%$ dos produtores. Dezenove por cento dos produtores se queixaram ainda de perdas elevadas em alevinos durante épocas quentes.

As perdas médias por ciclo também foi avaliada entre os produtores de tilápia do município de Morada Nova de Minas. No geral, os percentuais relatados apresentam uma variação de três a $33 \%$ de perdas por ciclo. Cinquenta por cento dos produtores relataram um 
percentual médio de $10 \%$ de perdas por ciclo. No entanto, os valores relatados são, em geral, pouco confiáveis, uma vez que grande parte dos produtores não possui um controle efetivo desses parâmetros, baseados apenas em estimativas. O gráfico 12 ilustra esses valores.

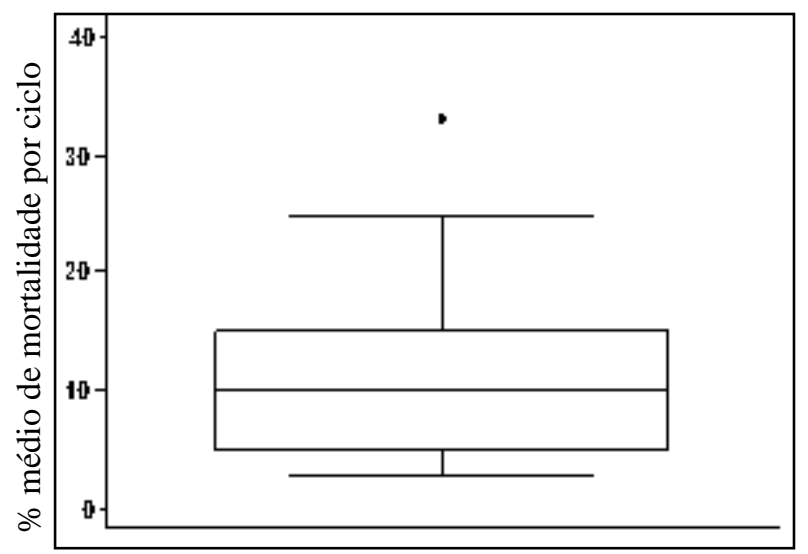

Gráfico 12. Percentual médio de perdas por ciclo da produção de tilápia em tanque-rede no município de Morada Nova de Minas, MG.

Um estudo realizado por Sabbag et al. (2007) no reservatório de Ilha Solteira (São Paulo) e outro realizado por Ayroza e Furlaneto (2006), no médio Paranapanema (São Paulo), encontraram taxa de mortalidade estimada em $15 \%$ em produção de tilápia em tanques-rede. No município de Morada Nova de Minas, $84 \%$ dos produtores relataram percentual médio de perdas por ciclo inferior a $15 \%$ e apenas $16 \%$ relataram perdas elevadas de mais de $15 \%$.

Independentemente da relação encontrada entre a taxa de mortalidade e a densidade de estocagem de animais por Garcia et al. (2013) e Leonardo e Baccarin (2014), nesse estudo não se identificou relação entre os índices de mortalidade nas propriedades com a densidade de animais por tanque. El-Sayed (2006) afirma que poucos estudos são realizados no sentido de associar o efeito dessas variáveis às perdas por ciclo, não havendo ainda uma definição de parâmetros a serem comparados.

Duas questões abertas foram realizadas para avaliar a percepção dos produtores quanto a pontos relevantes da aquicultura em reservatórios. As variáveis reveladas não foram préestabelecidas, caracterizando a verdadeira opinião dos produtores quanto às questões mais relevantes dessa atividade na região.

Perguntados sobre as principais variáveis que levam a perdas e mortalidades em seu sistema de produção, $72,4 \%$ dos produtores citaram condições ambientais, como clima e nível de água, como questões relevantes para as perdas de produção. A qualidade dos alevinos foi citada em seguida (31\%). Em menor frequência foram relatados problemas sanitários, como a inadequada limpeza e desinfecção de tanques $(6,9 \%)$ e a presença de patógenos $(6,9 \%)$, reconhecidas como relevantes por apenas dois produtores (gráfico 13).
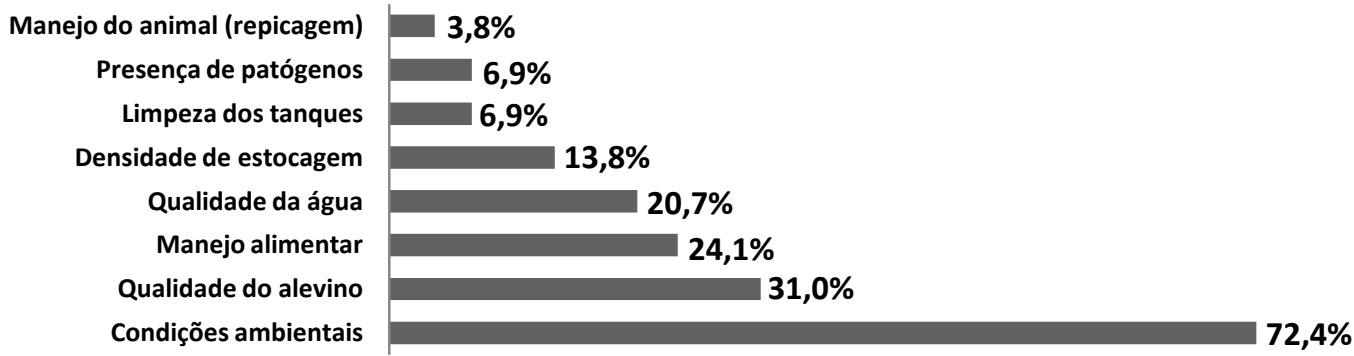

Gráfico 13. Percepção dos produtores de tilápia em tanque-rede quanto às principais causas de mortalidade de peixes em reservatórios no município de Morada Nova de Minas, MG. 
Com relação à percepção dos produtores quanto às principais dificuldades enfrentadas no setor de aquicultura em reservatório, questões como licenciamento ambiental, custo da ração e variações climáticas foram levantadas, conforme tabela 10.

Tabela 10. Principais desafios relatados pelos produtores de tilápia em tanque-rede quanto à produção de peixes no reservatório do município de Morada Nova de Minas, MG.

\begin{tabular}{|c|c|c|}
\hline Desafios do setor & Frequência de relatos & Descrição \\
\hline $\begin{array}{l}\text { Licenciamento } \\
\text { ambiental }\end{array}$ & $59,38 \%$ & $\begin{array}{l}\text { Considerado o principal desafio, os produtores encontram } \\
\text { dificuldade na obtenção do licenciamento ambiental por questões } \\
\text { burocráticas, impedindo a regularização do empreendimento e a } \\
\text { obtenção de crédito por parte do governo. }\end{array}$ \\
\hline Custo da ração & $34,38 \%$ & $\begin{array}{l}\text { Produtores queixam-se do aumento constante do preço da } \\
\text { ração, que representa aproximadamente } 70 \% \text { do custo total da } \\
\text { produção (Conte, 2002), valor esse que aumenta também devido à } \\
\text { ausência de fábricas de ração próximas ao município, encarecendo o } \\
\text { frete. }\end{array}$ \\
\hline $\begin{array}{l}\text { Variações climáticas } \\
\text { e ambientais }\end{array}$ & $31,25 \%$ & $\begin{array}{l}\text { Períodos de altas temperaturas, intensa variação climática } \\
\text { ao longo do dia ou baixo nível de água no reservatório, devido a } \\
\text { períodos de estiagem, são considerados, por alguns produtores, } \\
\text { como importantes fatores para o aparecimento de doenças nos } \\
\text { animais, levando a perdas consideráveis nos lotes. }\end{array}$ \\
\hline
\end{tabular}

Parte dos produtores queixa-se da dificuldade em se obter assistência técnica do governo para questões sanitárias, de manejo e burocráticas, considerando que muitos deles não têm muito conhecimento sobre as melhores técnicas de produção e nem condições de contratar assistência particular.

\begin{tabular}{|c|c|c|}
\hline $\begin{array}{l}\text { Escoamento } \\
\text { produção }\end{array}$ & $25,00 \%$ & $\begin{array}{l}\text { Alguns produtores relatam que um dos desafios do setor } \\
\text { é a pequena quantidade de unidades de beneficiamento do pescado, } \\
\text { dificultando o escoamento da produção principalmente em situações } \\
\text { de grande oferta do produto. }\end{array}$ \\
\hline $\begin{array}{l}\text { Valor de venda do } \\
\text { produto }\end{array}$ & $21,88 \%$ & $\begin{array}{l}\text { Em contraste com o alto custo da produção, em grande } \\
\text { parte devido ao preço da ração, produtores queixam-se do preço de } \\
\text { venda dos peixes que se mantém estável ou que pode até abaixar } \\
\text { devido à grande oferta, inclusive pelo aumento no número de novos } \\
\text { produtores que passam a produzir sem atenção a aspectos sanitários } \\
\text { e de manejo, comercializando o produto abaixo do valor de custo. }\end{array}$ \\
\hline $\begin{array}{l}\text { Financiamento } \\
\text { infraestrutura }\end{array}$ & $15,63 \%$ & $\begin{array}{l}\text { A dificuldade em se obter financiamento por parte do } \\
\text { governo se torna um desafio para alguns produtores que, } \\
\text { consequentemente, não podem investir em melhorias na } \\
\text { infraestrutura, como estradas de acesso, tanques, equipamentos e } \\
\text { medicamentos. }\end{array}$ \\
\hline $\begin{array}{l}\text { Obtenção de mão de } \\
\text { obra }\end{array}$ & $6,25 \%$ & $\begin{array}{l}\text { O produtor relata a dificuldade em se obter mão de obra } \\
\text { fixa e qualificada, queixando-se da dificuldade em manter um } \\
\text { mesmo funcionário por um período superior a } 4 \text { ou } 5 \text { meses. }\end{array}$ \\
\hline Qualidade da água & $6,25 \%$ & $\begin{array}{l}\text { A baixa qualidade da água, relatada por apenas um } \\
\text { produtor, é consequência, segundo ele, da poluição da água por } \\
\text { excesso de resíduos de fertilizantes e pesticidas advindos de } \\
\text { plantações agrícolas vizinhas. }\end{array}$ \\
\hline
\end{tabular}




\section{CONSIDERAÇÕES FINAIS}

Esses resultados permitiram conhecer a situação atual da aquicultura em tanques-rede em Morada Nova de Minas, reservatório de Três Marias, com relação a aspectos produtivos, sanitários e o perfil dos produtores.

De maneira geral, predominam na região sistemas de produção menores e com infraestrutura mínima, baixa incorporação de capital e baixa tecnologia. Há também um número reduzido de pessoas envolvidas no manejo produtivo e ausência de assistência técnica regular, caracterizando propriedades com baixo investimento. Essa pode ser uma razão pela qual a atividade no município ainda é baseada em métodos tradicionais de produção, não sendo observada a utilização de tecnologias mais atuais.

Segundo Sidonio et al. (2010), ainda é pouco comum no Brasil a presença de assistência técnica nessas propriedades. Esse suporte se mostra fundamental para a disseminação de boas práticas na atividade e para solucionar problemas de manejo, como excesso ou falta de ração, doenças e surtos de mortalidade. No entanto, muito deve ser considerado quanto à presença de assistência técnica nessas propriedades, visto que, por se tratarem de sistemas de baixo custo de produção, a contratação de um técnico ou de um médico veterinário pode não ser viável e os produtores optam por não adquiri-la.

A mão de obra é um fator relevante para a realidade do município, pois, além do número reduzido de funcionários, que acabam sobrecarregados com a quantidade de serviços a serem realizados na piscicultura, muitos produtores se queixam da alta rotatividade dos funcionários, se deparando, portanto, com mão de obra menos qualificada.

Grande parte dos piscicultores do município, recentemente inseridos na atividade, não atua exclusivamente na piscicultura. Além disso, a constante mudança do local de produção reflete a vulnerabilidade a condições ambientais e problemas de infraestrutura observados, $o$ que gera certa instabilidade no setor.

Com relação aos aspectos sanitários, medidas mínimas são tomadas e pouco esforço é feito no sentido de prevenir a transmissão de doenças, visto que poucos produtores têm conhecimento ou consideram a presença de patógeno um fator relevante para seu sistema de produção. A presença de assistência técnica e a atuação de órgãos de extensão garantiria maior instrução com relação às práticas adequadas de limpeza e desinfecção, administração de medicamentos e realização de testes diagnósticos.

Apesar das falhas estruturais observadas na aquicultura em tanques-rede no município de Morada Nova de Minas, a atividade vem crescendo ao longo dos anos, ainda que de forma desordenada. Apesar do risco vivenciado pelo baixo nível de água do reservatório nos últimos anos, há uma expectativa do município quanto à instalação de novas unidades produtivas, bem como unidades de beneficiamento e processamento da matéria prima.

Assim como no reservatório de Três Marias, a aquicultura em reservatórios do Brasil é uma atividade relativamente recente e revela o grande potencial de crescimento do país. Quando bem planejada, a atividade favorece a economia do país e permite o aproveitamento sustentável dos recursos naturais, contribuindo ainda para a geração de renda e criação de trabalho (Valenti, 2000). Espera-se que essa atividade aumente a competitivadade nos mercados nacionais e internacionais, com o aumento contínuo da produção em escala industrial. No entanto, o modelo de produção necessita de ajustes para reduzir os custos e o risco de transmissão de doenças e promover o crescimento do setor de acordo com o seu potencial.

Acompanhando o crescimento da aquicultura, a diversidade e o número de espécies produzidas podem ter contribuído para o surgimento e a disseminação de patógenos e para a ocorrência de doenças, considerada hoje uma das principais limitações para a expansão da atividade (Peeler e Taylor, 2011; Subasinghe, 2005). Baseado nisso, a aplicação de 
ferramentas epidemiológicas para identificar fatores de risco e para controlar e mitigar sua ocorrência se faz cada vez mais necessária no âmbito de animais aquáticos.

Apesar da relevância da ocorrência de doenças para o sistema de produção, a aplicação efetiva de medidas de biossegurança ao longo de toda a cadeia produtiva de peixes ainda não se encontra bem estabelecida no Brasil. A falta de recursos e informações relacionada aos aspectos sanitários é notável nos produtores do município de Morada Nova de Minas. Em geral, os produtores não são capazes de identificar o início da ocorrência de doenças ou de atribuir uma causa a elas. Aliado a isso, a ausência de assistência técnica, envolvendo o não diagnóstico de doenças e o uso indiscriminado de antibióticos por parte dos produtores, representa outro problema relacionado à sanidade dos animais aquáticos na região, bem como à saúde pública.

Diante disso, é indiscutível a importância da atuação conjunta do governo e do setor privado no direcionamento dos investimentos para a estruturação da cadeia produtiva.

A Instrução Normativa $n^{\circ} 4$, de 4 de fevereiro, publicada em 2015 pelo governo federal, que institui o Programa Nacional de Sanidade de Animais Aquáticos de Cultivo, visa atender essas exigências ao definir ações de prevenção, controle e erradicação de doenças nos cultivos de animais aquáticos (BRASIL, 2015b). Entretanto, a referida normativa ainda não se encontra em vigência.

Durante a realização do estudo, verificou-se que o serviço veterinário ainda carece de dados, treinamentos, capilaridade e recursos financeiros para realizar investigações epidemiológicas.

Os desafios encontrados para a expansão da atividade de aquicultura em tanques rede nos principais reservatórios do país enfatizam a importância da integração de diversos setores. A implementação de políticas públicas visando facilitar o acesso ao crédito e a regularização do empreendimento e a definição de programas de biossegurança que garantam a prevenção e o controle de doenças, permitem motivar e conscientizar os produtores quanto à utilização de ferramentas adequadas para o crescimento ordenado da atividade. Além disso, a organização do setor privado possibilitará aumentar a demanda e impulsionar a economia.

Por fim, a pesquisa científica se faz fundamental para o conhecimento da cadeia, buscando diagnosticar e solucionar falhas estruturais e orientar os produtores quanto às formas mais eficientes de produção e de redução das perdas, além de permitir que se avalie os padrões de disseminação de doenças para dar suporte à definição de políticas de saúde animal.

A caracterização da aquicultura em tanques-rede no município de Morada Nova de Minas, reservatório de Três Marias-MG, possibilitou revelar os aspectos produtivos e sanitários da região, permitindo diagnosticar falhas no sistema e pontos positivos a serem trabalhados e aperfeiçoados na atividade. No entanto, os resultados obtidos nesse estudo não devem ser generalizados à realidade de outros reservatórios, visto que cada região possui suas particularidades socioeconômicas, produtivas e ambientais.

A realização de pesquisas complementares no reservatório de Três Marias e a caracterização da aquicultura em outros reservatórios possibilitará traçar o perfil dessa atividade no Brasil, servindo como ferramenta para a tomada de decisões e garantindo o desenvolvimento do setor por meio de planejamento estratégico. 


\section{REFERÊNCIAS BIBLIOGRÁFICAS}

AYROZA, D.M.M.R.; FURLANETO, F.P.B; AYROZA, L.M.S. Regularização dos projetos de tanques-rede em águas públicas continentais de domínio da união no Estado de São Paulo. Boletim Técnico do Instituto de Pesca, São Paulo, v.36, 2006.

BARBOSA, A.C.A., MOURA, E.V. DE, SANTOS, R.V. Cultivo de tilápias em gaiolas. Circuito d. ed. EMPARN, Rio Grande do Norte - Natal, 2010.

BEVERIDGE, M. C. M. Cage and pen fish farm: carryng capacity models and environmental impact. Rome: FAO, 131 p, 1984.

BRASIL. IN n ${ }^{\circ}$ 6, de 31 de maio. Estabelece as normas complementares para a autorização de uso dos espaços físicos em corpos d'água de domínio da União para fins de aqüicultura, e dá outras providências. Secretaria Especial de Aquicultura e Pesca, 2004. Disponível em: <http://www.crmvgo.org.br/legislacao/2_AQUICULTURA/040531_IN_inter_06.pdf> (Acesso em Dezembro 2015).

BRASIL. Ministério da Pesca e Aquicultura - Parques Aquícolas, 2012. Disponível em: <http://www.mpa.gov.br/index.php/aquiculturampa/aguas-da-uniao/parques aquicolas/parquesaquicolas-continentais> (Acesso em Dezembro 2015).

BRASIL. Companhia de Desenvolvimento dos Vales do São Francisco e do Parnaíba CODEVASF, 2015 a. Disponível em: < http://www.codevasf.gov.br/noticias/2015/relatorioda-codevasf-divulga-dados-da-producao-em-tanques-rede-do-reservatorio-de-tres-marias$\mathrm{mg} />$ (Acesso em Janeiro 2016).

BRASIL. IN $n^{\circ} 4$, de 4 de fevereiro. Institui o programa nacional de sanidade de animais aquáticos de cultivo - "Aquicultura com sanidade". Ministério da Pesca e Aquicultura. DOU seção 1. P. 47-52, 2015 b. Disponível em: <http://www.mpa.gov.br> (Acesso em Janeiro 2016).

CARVALHO, E.D., CAMARGO, A.L.S., ZANATTA, A.S. Desempenho produtivo da tilápia do nilo em tanques-rede numa represa pública: modelo empírico de classificação. Ciência Rural. V. 40, 1616-1622. doi:10.1590/S0103-84782010000700021, 2010.

CONTE, F. Stress and the welfare of cultured fish. Appl. Anim. Behav. Sci. 86, 205-223. doi:10.1016/j.applanim.2004.02.003, 2004.

CONTE, L. Produtividade e Economicidade da Tilapicultura em Gaiolas na Região Sudoeste do Estado de São Paulo: Estudos de Casos 73, 2002.

EL-SAYED, A. - F.M. Intensive Culture. In: ABDEL-FATTAH M. EL-SAYED (Ed.)

Tilapia Culture, London, Cap.5, p.70-94, 2006.

ELTHOLTH, M., FORNACE, K., GRACE, D., RUSHTON, J., HÄSLER, B.

Characterisation of production, marketing and consumption patterns of farmed tilapia in the Nile Delta of Egypt. Food Policy. V. 51, 131-143. doi:10.1016/j.foodpol.2015.01.002, 2015. 
FAO. The state of world fisheries and aquaculture, Food and Agriculture Oraganization of the United Nations. doi:92-5-105177-1, 2014.

FRANCIS-FLOYD, R. Sanitation Practices for Aquaculture Facilities. Sanit. Pract. Aquac. Facil. 1-5. doi:VM87, 2000.

GARCIA, F., ROMERA, D.M., GOZI, K.S., ONAKA, E.M., FONSECA, F.S., SCHALCH, S.H.C., CANDEIRA, P.G., GUERRA, L.O.M., CARMO, F.J., CARNEIRO, D.J., MARTINS, M.I.E.G., PORTELLA, M.C. Stocking density of Nile tilapia in cages placed in a hydroelectric reservoir. Aquaculture. V. 410-411, 51-56.

doi:10.1016/j.aquaculture.2013.06.010, 2013.

GEORGIADIS, M.P., GARDNER, I. A., HEDRICK, R.P. The role of epidemiology in the prevention, diagnosis, and control of infectious diseases of fish. Prev. Vet. Med. 48, 287302. doi:10.1016/S0167-5877(00)00202-6, 2001.

KLONTZ, G. W. Environmental requirements and environmental diseases of salmonids. In: STOSKOPF, M (Ed.) Fish Medicine. Saunders, Philadelphia, PA, USA, PP. 333-342, 1993.

LAZZARI, R., BALDISSEROTTO, B. Nitrogen and Phosphorus Waste in Fish Farming. Inst. Pesca. São Paulo, 34 (4): 591-600, 2008.

LEONARDO, A.F., CORREAA, C.F., BACCARIN, A.E. Water quality of tilapia cage culture in rural reservoir in São Paulo South, Brazil. Bol. Inst. Pesca 37, 341-354. doi:Export Date 9 July 2012 \nSource Scopus, 2009.

LEONARDO, A.F.G., BACCARIN, A.E. Desempenho produtivo de tilápias do Nilo criadas em tanques rede em represa rural no Vale do Ribeira. Bol. Indústria Anim. 71, 256-261. doi:10.17523/bia.v71n3p256, 2014.

MARTINS, M. L.; MIYAZAKI, D. K. Y; MOURIÑO, J. L. P. Aeromonas caviae durante surto de mortalidade em tilápia do Nilo e suplementação com vitamina $\mathrm{C}$ na dieta. Boletim do Instituto de Pesca, 34 (4), 585 - 590, 2008.

MPA, Ministério da Pesca e Aquicultura, Secretaria de Monitoramento e Controle - SEMOC, 2013. Boletim da Pesca e Aquicultura, 2011. Disponível em:

<http://www.mpa.gov.br/files/docs/Boletim_MPA_2011_pub.pdf> (Acesso em Dezembro 2015).

OIDTMANN, B.C., CRANE, C.N., THRUSH, M. A., HILL, B.J., PEELER, E.J. Ranking freshwater fish farms for the risk of pathogen introduction and spread. Prev. Vet. Med. 102, 329-340. doi:10.1016/j.prevetmed.2011.07.016, 2011.

PEELER, E.J., TAYLOR, N.G. The application of epidemiology in aquatic animal health opportunities and challenges. Vet. Res. 42, 94. doi:10.1186/1297-9716-42-94, 2011.

SABBAG, O.J; ROZALES, R. DOS R; TARSITANA, M.A.A; SILVEIRA, A.N. Análise econômica da produção de tilápias (Oreochromis niloticus) em um modelo de propriedade associativista em Ilha Solteira/SP. Custos e Agronegócio Online, v. 3, n. 2, Jul/Dez, 2007. 
SAMPAIO, F.G., LOSEKANN, M.E., JOSÉ, A., LUIZ, B., NEVES, M.C., FRASCÁSCORVO, C.M.D. Monitoramento e gestão ambiental da piscicultura em tanques-rede em reservatórios. Inf. Agropecuário, 34, 1-11, 2013.

SIDONIO, L., CAVALCANTI, I., CAPANEMA, L., MORCH, R., MAGALHÃES, G., LIMA, J., BURNS, V., JOSÉ, A., JÚNIOR, A., MUNGIOLI, R. Panorama da aquicultura no Brasil: desafios e oportunidades. BNDES Setorial 35, 421-463, 2010.

SUBASINGHE, R.P. Epidemiological approach to aquatic animal health management: Opportunities and challenges for developing countries to increase aquatic production through aquaculture. Prev. Vet. Med. 67, 117-124, 2005. doi:10.1016/j.prevetmed.2004.11.004.

TORNIMBENE, B., CHHIM, V., SORN, S., DREW, T.W., GUITIAN, J. Knowledge, attitudes and practices of Cambodian swine producers in relation to porcine reproductive and respiratory syndrome (PRRS). Prev. Vet. Med. 116, 252-67, 2014.

doi:10.1016/j.prevetmed.2013.12.009

VALENTI, W. C. Introdução. In: VALENTI, W. C.; POLI, C. R.; PEREIRA, J. A.; BORGHETTI, J. R. (Ed.). Aquiicultura no Brasil: bases para um desenvolvimento sustentável. Brasília, DF: CNPq: Ministério da Ciência e Tecnologia. p. 25-32, 2000.

WATANABE, W.O., LOSORDO, T.M., FITZSIMMONS, K., HANLEY, F. Tilapia Production Systems in the Americas: Technological Advances, Trends, and Challenges. Rev. Fish. Sci. 10, 465-498, 2002. doi:10.1080/20026491051758

ZAGO, A. C. Análise parasitológica e microbiológica de tilápias do Nilo (Oreochromis niloticus) criadas em tanques-rede no reservatório de Água Vermelha - SP e suas interrelações com as variáveis limnológicas e fase de criação. Dissertação de Mestrado.

Universidade Estadual Paulista, Instituto Biociência de Botucatu, Botucatu, SP, p. 69, 2012. 